\title{
Forced vibration and hygrothermal analysis of composite laminated beams under the action of moving loads
}

Praveen Kumar Kavipurapu
West Virginia University

Follow this and additional works at: https://researchrepository.wvu.edu/etd

\section{Recommended Citation}

Kavipurapu, Praveen Kumar, "Forced vibration and hygrothermal analysis of composite laminated beams under the action of moving loads" (2005). Graduate Theses, Dissertations, and Problem Reports. 1601. https://researchrepository.wvu.edu/etd/1601

This Thesis is protected by copyright and/or related rights. It has been brought to you by the The Research Repository @ WVU with permission from the rights-holder(s). You are free to use this Thesis in any way that is permitted by the copyright and related rights legislation that applies to your use. For other uses you must obtain permission from the rights-holder(s) directly, unless additional rights are indicated by a Creative Commons license in the record and/ or on the work itself. This Thesis has been accepted for inclusion in WVU Graduate Theses, Dissertations, and Problem Reports collection by an authorized administrator of The Research Repository @ WVU. For more information, please contact researchrepository@mail.wvu.edu. 
Forced Vibration and Hygrothermal Analysis of Composite Laminated

Beams under the Action of Moving Loads

\title{
Praveen Kumar Kavipurapu
}

\author{
Thesis submitted to the \\ College of Engineering and Mineral Resources \\ at West Virginia University \\ in partial fulfillment of the requirements \\ for the degree of
}

Master of Science

in

Mechanical Engineering

Nithi T. Sivaneri, Ph.D., Chair

Kenneth H. Means, Ph.D.,

Bruce S. Kang, Ph.D.,

Department of Mechanical and Aerospace Engineering

Morgantown, West Virginia

2005

Keywords: Composite Beams, Hygrothermal, Moving Loads, Finite Element Method. 


\section{ABSTRACT \\ Forced Vibration and Hygrothermal Analysis of Composite Laminated \\ Beams under the Action of Moving Loads}

\section{Praveen Kumar Kavipurapu}

The dynamic response of simply supported glass/epoxy composite beams subjected to moving loads in a hygrothermal environment is carried out using the general purpose finite element program ANSYS. The moving load model and the hygrothermal incorporation are validated separately by reproducing results available in the literature. The hygrothermal effect is introduced by using empirical relations for degrading the material stiffness properties of the matrix. The corresponding ply properties are calculated using the rule of mixtures. A parametric study is conducted by varying the fiber volume fraction and the fiber orientation of the angle plies in the laminate. The results indicate that the dynamic magnification factors generally increase due to hygrothermal effects but all the laminates considered do not behave in a similar manner. Thus it is possible to minimize the environmental effect by judiciously selecting the laminate configuration. 


\section{ACKNOWLEDGEMENTS}

Completing this thesis, although was a challenge for me, would not have achieved without the support, inspiration, encouragement and contribution of many people. First of all, I would like to take this opportunity to express my profound thanks to my advisor Dr. Nithi Sivaneri for his excellent mentorship throughout my stay and studies at West Virginia University. Without him things would have never worked better than this.

I would like to express my gratitude to Dr. Bruce Kang and Dr. Kenneth Means

for being my thesis committee members and for their valuable suggestions in directing my efforts to present my work as a complete thesis.

I would like to express my gratefulness to my parents and my brother, Vijay Kavipurapu who have always supported my vision and have given me timely guidance, support and inspiration until now in every aspect of my education.

I would also like to express my special thanks to my friends Amarnath Santosh Varthakavi, Gaurav Srivastava, Murali Gadde, Sameera Dasari, Chakradhar Pillala, Jaya Munjuluri, Madhubala Munjuluri, Sachin Agarwal, and Hem Chander Mada who have contributed in countless ways, in completing my studies and thesis. 


\section{TABLE OF CONTENTS}

ABSTRACT

ACKNOWLEDGMENTS iii

LIST OF SYMBOLS vi vi

LIST OF TABLES vii

LIST OF FIGURES — ix

1 INTRODUCTION 1

1.1 Problem statement 1

1.2 Laminated composites 1

1.3 Literature review 2

1.4 Need for present study $\quad 8$

1.5 Objectives 9

1.6 Thesis overview 9

2 THEORETICAL FORMULATION 10

2.1 Introduction $\quad 10$

2.2 Composite Lay-up Configuration 10

2.2.1 Force and Moment Resultants 11

2.2.2 Composite Plate Theories 12

2.3 Hygrothermal Analysis 13

2.4 Governing Equations for Cylindrical Bending of Plates 16

3 FINITE ELEMENT MODELING 19

3.1 Introduction $\quad 19$

3.2 Overview of ANSYS 19

3.2.1 Modeling in ANSYS of present problem 20

3.3 Boundary Conditions and Meshing 23

3.3.1 Meshing 23

3.4 Modal Analysis $\quad 24$

3.4.1 Subspace method of mode extraction 25

3.5 Transient Dynamic Analysis $\quad 25$

4 RESULTS AND DISCUSSION 27

4.1 Introduction $\quad 27$

4.2 Isotropic Beam Comparison $\quad 27$

4.2.1 Static Central Deflection of Simply Supported Isotropic Beam 28

4.2.2 Moving Force on a Simply Supported Isotropic Beam 28

4.3 Composite Beam subjected to Moving Load 33

4.4 Hygrothermal Analysis on Composite Laminated Beams 39 
4.4.1 Dry Conditions $\quad 40$

4.4.1.1 Transverse Deflections of Pinned-Pinned Laminated 40 Composite Beam under Uniform Transverse Load

4.4.1.2 Transverse Deflections of Clamped-Clamped Laminated 43 Composite Beam under Uniform Transverse Load

4.4.1.3 Transverse Deflections of Pinned-Pinned Laminated 44

Composite Beam under In-Plane Loads

4.4.2 Hygrothermal Conditions 46

4.5 Comparison of Hygrothermal Deflections with that of Dry Conditions for $\quad 50$

Laminate under Cylindrical Bending

4.6 Composite Beam subjected to Moving Loads under Hygrothermal 53

Environment

4.6.1 Static Analysis $\quad 54$

4.6.2 Dynamic Analysis 56

4.6.3 Dynamic Magnification Factors $\quad 57$

5 CONCLUSIONS AND RECOMMENDATIONS 61

$\begin{array}{ll}5.1 \text { Contributions } & 61\end{array}$

$\begin{array}{ll}5.2 \text { Conclusions } & 61\end{array}$

$\begin{array}{ll}5.3 \text { Recommendations } & 62\end{array}$

$\begin{array}{ll}\text { REFERENCES } & 63\end{array}$ 


\section{LIST OF SYMBOLS}

\begin{tabular}{ll}
$a$ & Half span of laminate (in.) \\
{$[A]$} & Axial stiffness matrix (lb/in.) \\
{$[B]$} & Bending-extension stiffness matrix (lb) \\
{$[D]$} & Bending stiffness matrix (lb-in.) \\
$E$ & Modulus of elasticity (lb/in. $\left.{ }^{2}\right)$ \\
$\left\{F^{e}\right\}$ & External element force vector \\
$h$ & Height of laminate (in.) \\
$I$ & Moment of inertia (in. ${ }^{4}$ ) \\
{$[K]$} & Global stiffness matrix (lb/in.) \\
$\left\{K^{e}\right\}$ & Element stiffness matrix (lb/in.) \\
$L$ & Length of beam (in.) \\
$M_{x}, M_{y}, M_{x y}$ & In plane moment resultants in $x y$ plane (lb) \\
$m$ & Moisture content (\%) \\
$n$ & Number of layers \\
$N_{x}, N_{y}, N_{x y}$ & In plane force resultants in $x y$ plane (lb/in.) \\
$P$ & Vertical static load (lb) \\
$\left\{q^{e}\right\}$ & Nodal values of generalized displacement (in.) \\
$q$ & Uniform transverse load (lb/in. $\left.{ }^{2}\right)$ \\
$t$ & Time (s) \\
$t_{k}$ & Thickness of $k^{\text {th }}$ layer (in.) \\
$u$ & Displacement in the $x$ direction (in.) \\
$V_{f}$ & Fiber volume fraction \\
$w$ & Transverse deflection (in.) \\
$x, y$ & In-plane coordinates \\
$z$ & Thickness coordinate \\
$z_{k}$ & Distance to the top of the $k^{\text {th }}$ layer from the mid-plane of a laminate (in.) \\
\hline$z_{k}$ & Distance to mid surface of the $k^{t h}$ layer from the mid-plane of a laminate (in.) \\
$\delta_{s}$ & Static deflection of the beam (in.) \\
$\delta_{d}$ & Dynamic deflection of the beam (in.) \\
$\varnothing$ & Relative humidity \\
$\rho$ & Mass density \\
&
\end{tabular}




\section{LIST OF TABLES}

4.1 Static mid-span deflection of a simply supported beam 28

$\begin{array}{lll}4.2 & \text { Moving load velocities and time steps } & 29\end{array}$

4.3 Maximum centre deflection for various moving load velocities 30

4.4 Dynamic magnification factors for moving force on isotropic beam 30

4.5 Geometric and material properties of composite beam 33

4.6 Dynamic magnification factors for moving load on composite beam 35

$4.7 \quad$ Constituent properties of S glass fiber and Epoxy matrix 40

4.8 Parameters in hygrothermal analysis 40

4.9 Transverse deflections for pinned-pinned laminate due to transverse 41 load in dry condition

4.10 Transverse deflections for clamped-clamped laminate due to 43 uniform transverse load in dry condition

4.11 Transverse deflections for pinned-pinned laminate due to in-plane load 44 in dry condition

4.12 Transverse deflections for pinned-pinned laminate due to transverse 46 load for hygrothermal condition

4.13 Transverse deflections for clamped-clamped laminate due to 47 uniform transverse load in hygrothermal condition

4.14 Transverse deflections for pinned-pinned laminate due to in-plane load $\quad 49$ in hygrothermal condition

4.15 Dry and wet condition mid-span deflections of pinned laminate 51 under transverse load

4.16 Dry and wet condition mid-span deflections of clamped laminate 52 under transverse load

4.17 Dry and wet condition mid-span deflections of pinned laminate 53 under in-plane load 
4.18 Material properties for fiber volume fraction of $0.52 \quad 54$

4.19 Material properties for fiber volume fraction of $0.6 \quad 55$

4.20 Material properties for fiber volume fraction of $0.7 \quad 55$

4.21 Static mid-span deflection of beams made of various laminate 56 configurations

4.22 Dynamic mid-span deflections of beams made of various 57 laminate configurations

4.23 Dynamic magnification factors for different lay-ups and $V_{f} \quad 58$ 


\section{LIST OF FIGURES}

2.1 Simply supported beam subjected to a moving load 10

2.2 Composite lay-up configuration 11

2.3 In-Plane forces and moment resultants 12

2.4 Deformation of transverse normal for CLPT, FSDT, HSDT 13

2.5 Laminate subjected to in-plane load, $N_{x} \quad 17$

2.6 Laminate subjected to uniform pressure load, $q \quad 17$

3.1 Simply supported beam subjected to moving load 20

3.2 Beam 3, 2-D Elastic Beam 21

3.3 Solid 191 Element 22

3.4 Shell 99 Element $\quad 22$

4.1 Dynamic magnification factor of an isotropic beam 31

4.2 Time history mid span deflection for velocity $V=51.16 \mathrm{ft} / \mathrm{s} \quad 31$

4.3 Time history mid span deflection for velocity $V=102.33 \mathrm{ft} / \mathrm{s}$

4.4 Time history mid span deflection for velocity $V=204.66 \mathrm{ft} / \mathrm{s}$

4.5 Time history mid span deflection for velocity $V=820.16 \mathrm{ft} / \mathrm{s}$

4.6 Dynamic magnification factor for composite laminated beam 35

4.7 Time history mid span deflection for velocity $V=51.16 \mathrm{ft} / \mathrm{s}$

4.8 Time history mid span deflection for velocity $V=102.33 \mathrm{ft} / \mathrm{s}$

4.9 Time history mid span deflection for velocity $V=204.66 \mathrm{ft} / \mathrm{s}$

4.10 Time history mid span deflection for velocity $V=307.08 \mathrm{ft} / \mathrm{s}$

4.11 Time history mid span deflection for velocity $V=409.06 \mathrm{ft} / \mathrm{s} \quad 38$

4.12 Time history mid span deflection for velocity $V=511.75 \mathrm{ft} / \mathrm{s}$

4.13 Time history mid span deflection for velocity $V=820.16 \mathrm{ft} / \mathrm{s}$

4.14 Pinned-pinned boundary conditions on composite laminate 41

4.15 Deflections for pinned-pinned laminate for uniform transverse load in dry 42 condition

4.16 Transverse deflection distribution for $0.0348 \mathrm{psi} \quad 42$ 
4.17 Deflections of clamped-clamped laminate for uniform transverse load in dry condition

4.18 Transverse deflection distribution for $0.0363 \mathrm{psi}$

4.19 Transverse deflections of pinned-pinned laminate under different tensile normal in-plane load in dry condition

4.20 Transverse deflection distribution for $3.426 \mathrm{lb} / \mathrm{in}$.

4.21 Transverse deflections of pinned-pinned laminate for different uniform transverse loads in hygrothermal condition

4.22 Transverse deflection distribution for $0.0348 \mathrm{psi}$

4.23 Transverse deflections of clamped-clamped laminate due to uniform transverse loads in hygrothermal condition

4.24 Transverse deflection distribution for 0.0363 psi

4.25 Transverse deflections for pinned-pinned laminates for different in-plane loads in hygrothermal condition

4.26 Transverse deflection distribution for $3.426 \mathrm{lb} / \mathrm{in}$.

4.27 Dry and wet condition mid span deflections of pinned-pinned laminate under transverse loads

4.28 Dry and wet condition mid span deflections of clamped-clamped laminate under transverse loads

4.29 Dry and wet condition mid span deflections of pinned-pinned laminate under in-plane loads

4.30 Dynamic magnification factor for 0/90/-15/15 laminate

4.31 Dynamic magnification factor for 0/90/-30/30 laminate 


\section{INTRODUCTION}

\subsection{Problem Statement}

The use of composite materials in engineering applications is increasing rapidly. Composite materials have higher strength-to-weight and stiffness-to-weight ratios than metals and find many applications such as composite bridge decks. Therefore, it is very important to understand the response of composite bridges to vehicle-induced vibrations. The strength, stiffness and eventually the life of composite bridges are affected more than conventional materials by the presence of moisture and temperature. Thus it is necessary to analyze the response of composite bridge decks under a hygrothermal environment.

\subsection{Laminated Composites}

A composite lamina consists of two or more distinct materials, combined at the macroscopic level, to attain desired properties that could not be achieved by either of the constituent materials alone. Composite materials can be divided into fibrous composites, particulate composites and laminated composites.

A laminate is a stack of lamina, with different fiber orientations, bonded together to attain desired properties. Laminates can be classified as symmetric, unsymmetric, balanced and unbalanced composites. In a symmetric laminate, the material and orientation of layers above the mid plane are identical to those below.

In a symmetric laminate the bending-stretching coupling is absent. That means, due to application of in-plane loads, bending and twisting curvatures will not be generated. This is not true for unsymmetric laminates. 
The analysis of composite structures is more complex and several theories have been proposed for the analysis of laminated composites. Composite laminates have larger planar dimensions, so they can be treated as plate elements. Therefore, plate theories can be applied in the analysis of laminated composites. Classical Laminate theory (CLT) and First Order Shear Deformation Theory (FSDT) are the two most commonly used theories for the analysis [Reddy (1997)]. The plate theories can be systematically reduced to analyze beams.

\subsection{Literature Review}

The dynamic response of the beams subjected to moving loads has been of interest from the early 1900's. The goal of these studies has always been to design and build safe, economical, and durable bridges. In general the stresses and deflections produced due to moving loads are higher than that of stationary loads. Therefore, proper estimate of the dynamic effect of moving loads is very important to evaluate the loadcarrying capacity of a beam. In the modern era, isotropic beams are replaced by lightweight and high-strength composite materials.

The dynamic response of bridge structures depends on many factors, which include vehicle configuration, pavement roughness and bridge parameters [(Cantieni, (1983); Chan and O’ Connor, (1990)]. Much research has been done to find the influence of various factors on the response of bridges. Various computer models have been developed in simulating vehicle-bridge interaction [(Chang and Lee, (1994) and Fafard et al., (1998)]. Bridge models in these studies range from simple to very complex finite element simulations. The vehicle models encompass the spectrum of a single moving 
force to complex ones with multidegree of freedom systems with suspensions, dashpots, and a concentrated mass representing the body of the vehicle.

Gonzalez and Brien (2001) have studied the dynamics of weight in motion considering the bridge and truck dynamics. In their work, they have investigated the parameters that affect the response of the bridge when a truck passes over it. The various parameters considered in this study are the road roughness, suspension type, and vehicle speed. In their simple case of a one-dimensional model, the bridge is a simply supported beam and the truck is composed of a body, suspension system and tires. The body of the vehicle is represented by a concentrated mass, while a mass element and a linear spring represent the cushioning effect of the tire.

In the same study, a moving load of constant magnitude acting on a beam has been considered. In this case, the mass of the load is neglected whereas the distributed mass of the beam is taken into account. The deflection of the beam is expressed in terms of modal coordinates and natural modes. LaGrange's equations are used to derive the equations of motion for each modal coordinate. It was found from this study that the only parameter that affects the bridge response is the vehicle speed.

Pesterev et al. (2001) have considered the vibration of a beam subjected to a constant moving force. They formulate simple tools to calculate the maximum deflection of the beam for any given velocity of the moving force. It is shown that there exists a unique response-velocity dependence function, which satisfies a particular boundary function.

A unique amplitude-velocity dependence function is formulated for simply supported and clamped-clamped beams. These unique functions are used to calculate the 
maximum beam response without complex computations. The response of the beam is approximated by means of the first natural mode. The response is also calculated by including higher modes. These responses are compared with each other and the error range is less than one percent. Therefore, it is concluded from this study that the first fundamental mode alone is sufficient for finding the maximum deflection of a beam when subjected to a moving force.

O’Connor and Chan (1988) have defined some methods to predict the structural dynamic response of bridges subjected to moving loads. These methods are often referred to as predictive analysis problems. In this type of analysis two beam models are used to predict the response of a structure: one is a discrete beam model and other a continuous beam model. In the discrete beam model, the bridge is modeled as an assembly of lumped masses connected by massless beam elements. From the dynamic response equations, the nodal displacements and bending moments are calculated. In the continuous beam model, an Euler-Bernoulli beam is taken into consideration. In this beam model, the effects of shear deformation and rotary inertia are neglected. The beam has a constant cross section and mass per unit length with a linear viscous damping. The load is assumed to move from one end to the other with constant velocity. By using modal superposition, the beam deflection is found at any instant of time and distance.

Chan et al. (1998) have proposed an interpretive method to identify dynamic moving loads based on the response of the bridge due to these loads. Basically, this method is the inverse of the predictive analysis problem stated by O'Connor and Chan (1988). Euler's equations are used to identify the moving force. Bending moments and displacements of the bridge are calculated using strain gauges and transducers. These 
responses are then used to identify constant and time varying moving forces. It is concluded that the identification using bending moments gives accurate results compared with that using displacements.

Saadeghvaziri (1993) has illustrated how a finite element package can be used to evaluate the dynamic transient effect of a moving load traversing a highway bridge. This is accomplished by using the load arrival time option in ADINA. The structure is assumed to be made of isotropic beam elements. The fundamental period of the bridge and the slowest velocity are taken into account to determine the number of elements. The weight of the moving load is neglected compared to that of the bridge and the velocity is assumed to be constant. The ratio of the time to travel the length of one element to the period of the highest mode is taken to be very small. This helps in avoiding unrealistic dynamic amplifications. The beam is assumed to be simply supported and subjected to a moving load of constant magnitude which travels from one end of the beam to the other. By using the load arrival time option in ADINA, the mid-span deflection and bending moments are determined. These results are compared and verified with exact analytical solutions.

A report submitted to the Virginia Transportation Research Council by Martin et al. (2000) describes the effect of design parameters on the dynamic response of a bridge. The commercial code ANSYS is used to simulate the moving load effect on the bridge structure. The effect of the damping is neglected in this analysis. The bridge is modeled using three dimensional isotropic beam elements. This beam model has the same dimensions and properties as the analytical model. The static and dynamic analysis results are compared with the analytical solution. This comparison validates the model 
and the method of load representation in ANSYS. The stiffness and mass of the beam, loading frequency, and vehicle speed are varied to determine the dynamic response. These results are compared with the corresponding static load cases to gauge the relative effects of these parameters on dynamic response.

Taheri (1987) has studied the dynamic response of plates to moving loads. In his work, he develops numerical procedures for the study of dynamic interactions between moving vehicles and supporting guide way systems. Two computer programs PLATEFEM and PLATEIMP have been developed to analyze the responses of a simply supported isotropic beam and plate due to a moving vehicle. The accuracy of the code is verified by finding the dynamic magnification factors at the centre of the beam/plate and comparing with analytical solutions. A parametric study is conducted to find the effects of different parameters on the dynamic response of plates. These parameters include damping of the foundation, velocity of the moving load, and thickness of the plate. The following conclusions are drawn from this study. The shape of the deflection curve of a plate produced by a moving vehicle is quite different from that due to a static load. This difference is more significant for a moving mass solution.

Kadivar and Mohebpour (1997) have studied the dynamic response of an unsymmetric orthotropic laminated beam when subjected to moving loads. A onedimensional element with 24 degrees of freedom is considered for the analysis. The effects of shear deformation and rotary inertia are also included. Orthotropic cross-ply and unsymmetric angle ply laminated beams are analyzed and the results are compared with those of an isotropic beam. Classical lamination theory, first order shear deformation theory, and higher-order shear deformation theory are used in the analysis of these 
laminated beams. It is concluded that shear deformation and inertia effects can be neglected in the analysis of isotropic beams; but, for composite beams these effects play a significant role in the dynamic analysis.

Tita, Carvalho, and Lirani (2003) have experimentally studied the dynamic analysis of fiber reinforced composite beams. Beams with different lay ups have been manufactured using hand lay up and molding processes. Dynamic tests have been conducted to analyze the influence of fiber orientation on natural frequencies and modal damping. The experimental results are compared with that from a finite element analysis.

Pipes et al. (1976) have studied the hygrothermal response of laminated composite systems. A plate element is used to analyze the laminae stresses resulting from hygrothermal and mechanical loading. A six-ply graphite/epoxy laminate is considered for the analysis of hygrothermal effects. The effective moisture bending and in plane force resultants are developed and combined with thermal loads.

Shen and Springer (1976) have studied the effects of moisture and temperature on ultimate strength of Thornel 300/Fiberite 1034 epoxy composite. Eight-ply T300/1034 specimens have been placed in environmental chambers in which temperature and relative humidity have been controlled and kept constant. The ultimate tensile strength has been measured with material temperatures and moisture contents ranging from $200^{\circ} \mathrm{K}$ to $422^{\circ} \mathrm{K}$ and $0 \%$ to $1.5 \%$, respectively. It is found that the ultimate strengths of $0^{\circ}$ and $45^{\circ}$ laminates have negligible change due to variation of temperature and moisture. But, in the case of $90^{\circ}$ laminates, the reduction in strength is as high as 60 to $90 \%$.

Upadhyay and Lyons (2000) have studied the effect of hygrothermal conditions on PMC laminates. The hygrothermal conditions are incorporated by changing the 
stiffness coefficients of the laminate. Empirical relations between the moisture content and temperature level are given by Chamis (1983). Large deflection theory is adopted in calculating the deflections and the results are compared to that of a linear theory. PinnedPinned, clamped-clamped laminates are considered in this study. Two types of loads, namely, in-plane and uniform transverse load are applied on these laminates. It is found that the presence of moisture and temperature in a laminate significantly affects the deflections caused by the loads. It is also observed that the linear theory yields high differences between dry and wet results.

\subsection{Need for Present Research}

The use of composite materials in the modern engineering applications has been increasing rapidly. Bridges, aerospace structures are few examples of their application. Steel bridges are replaced by composite materials due to their superior qualities like higher strength-to-weight ratio. Bridge structures are constantly being exposed to various types of loads. The major loads that influence the life of a bridge are dynamic moving loads, hygrothermal loads and wind loads.

The study of stiffness degradation of composite structures due to hygrothermal environment is crucial in evaluating the service life of the structure. In reality, bridges are under constant influence of moving and hygrothermal loads. From the survey of the related literature, it is evident that the feasibility of using a commercial code such as ANSYS for modeling the effect of moving loads on composites has not been demonstrated. Further the combined effects of moving loads and hygrothermal exposure has not been studied. The present research attempts to fill these voids. 


\subsection{Objectives}

- $\quad$ To simulate the effect of a moving load on simply supported isotropic and composite beams on ANSYS and to calculate dynamic deflection factors of the beam under various velocities of the moving load.

- $\quad$ To conduct a hygrothermal analysis of beams made of PMC laminates under the action of moving loads; to compare the transverse deflections of these beams under various boundary conditions for dry and wet environments.

- $\quad$ To conduct parametric studies involving the moving load analysis on laminated beams in dry and hygrothermal conditions.

\subsection{Thesis Overview}

Chapter Two explains the theory behind the present study. It deals with composite lay-up configurations and various theories that govern the composite behaviors. The formulation of governing equations and the equations that ANSYS solves in the analysis are discussed.

In chapter Three the finite element modeling of the present problem in ANSYS is detailed. The types of analysis used are outlined.

Chapter Four presents the results obtained in the present study. The graphs obtained from Ansys program are attached here.

Chapter Five has the conclusions of the present study and recommendations for the future work. 


\section{THEORETICAL FORMULATION}

\subsection{Introduction}

This chapter explains the theoretical formulation that governs the dynamic response of a composite beam subjected to a moving load. The governing equations for the hygrothermal effect on the laminated composites are also explained here. The main theories in the modeling of composite laminates are also described in detail. In modern industry, heavy traditional materials are being substituted with light and strong composite materials. Bridges and railroads made of composite laminates are considerably affected by moving loads, temperature, and moisture. Therefore, it is very important to analyze these effects which would find practical applications in engineering designs.

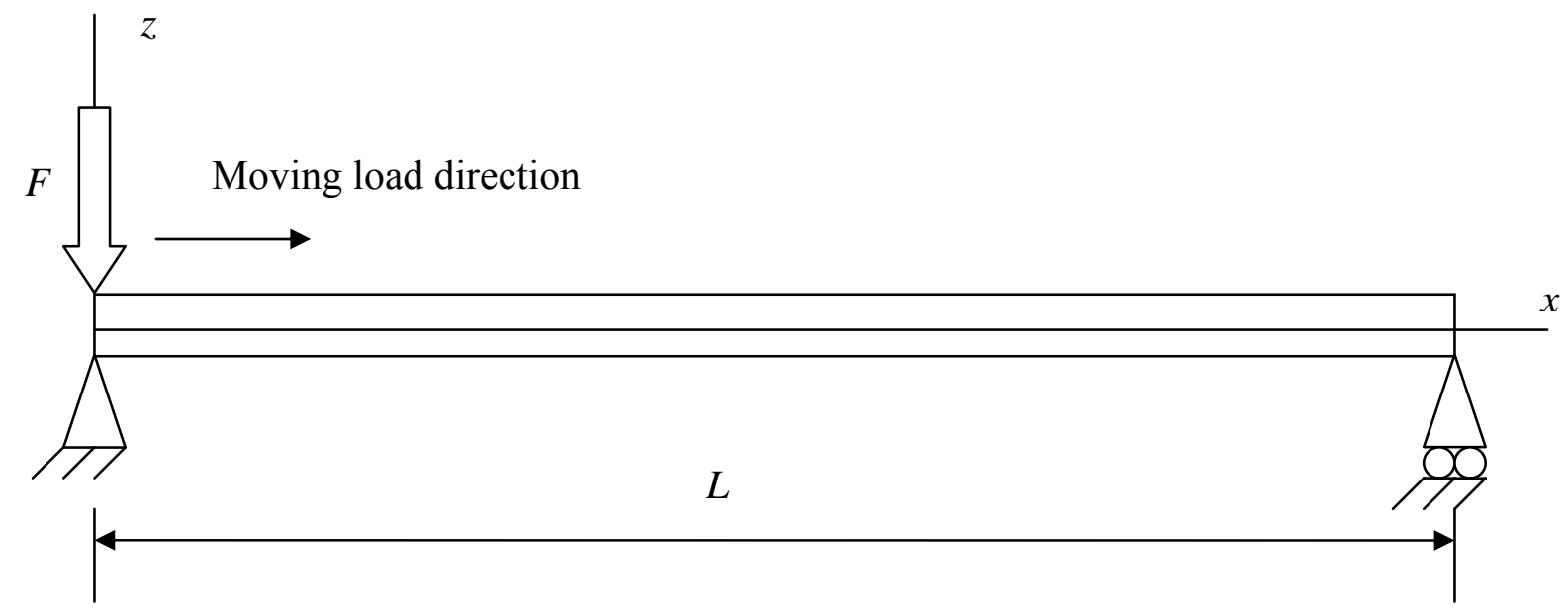

Fig 2.1 Simply supported beam subjected to a moving load

\subsection{Composite Lay-up Configuration}

Figure 2.2 shows the lay-up configuration and the normal conventions that are used to describe a composite laminate. It consists of $N$ layers numbered 1 to $N$ from the bottom to the top of laminate. The total thickness of the laminate is represented by $h$. The 
lateral coordinate $z$ is measured from a reference plane located at the mid-surface of the laminate. The quantity $z_{k}$ represents the distance of the top of the $k^{\text {th }}$ layer from the reference plane. The quantity $\overline{z_{k}}$ represents the $z$ coordinate of the middle surface of the $k^{\text {th }}$ layer.

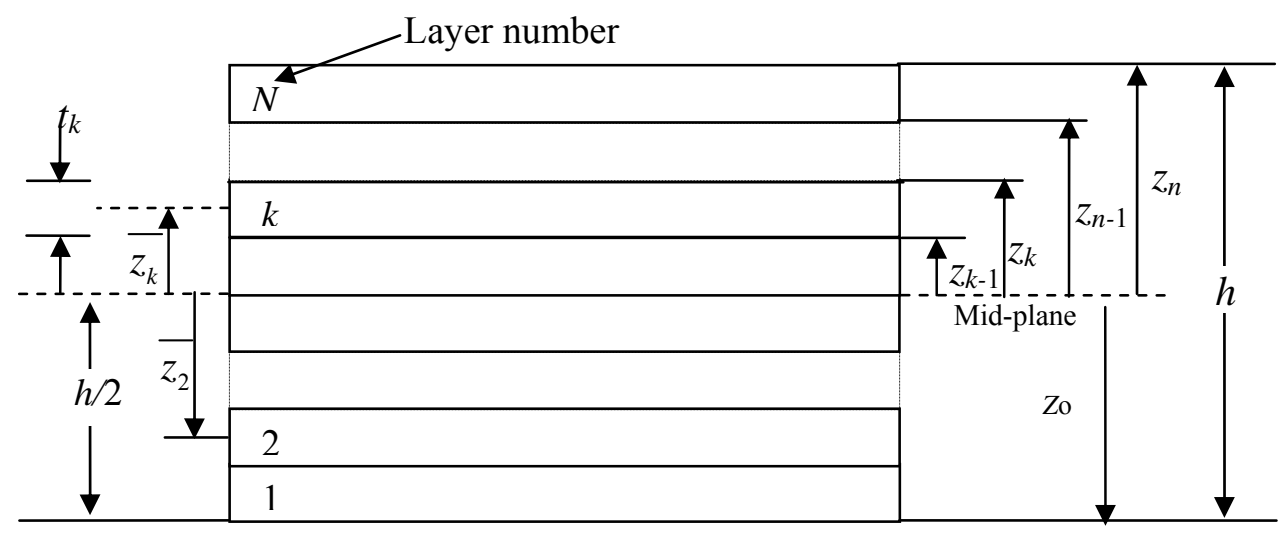

Figure 2.2 Composite lay-up configuration

\subsubsection{Force and Moment Resultants}

Figure 2.3 shows the positive directions of force and moment resultants acting on a plate. The $N_{X}, N_{Y}, N_{X Y}$ are the in plane force resultants and $M_{X}, M_{Y}, M_{X Y}$ are the moment resultants, and $V_{X}, V_{Y}$, the transverse shear force resultants. 

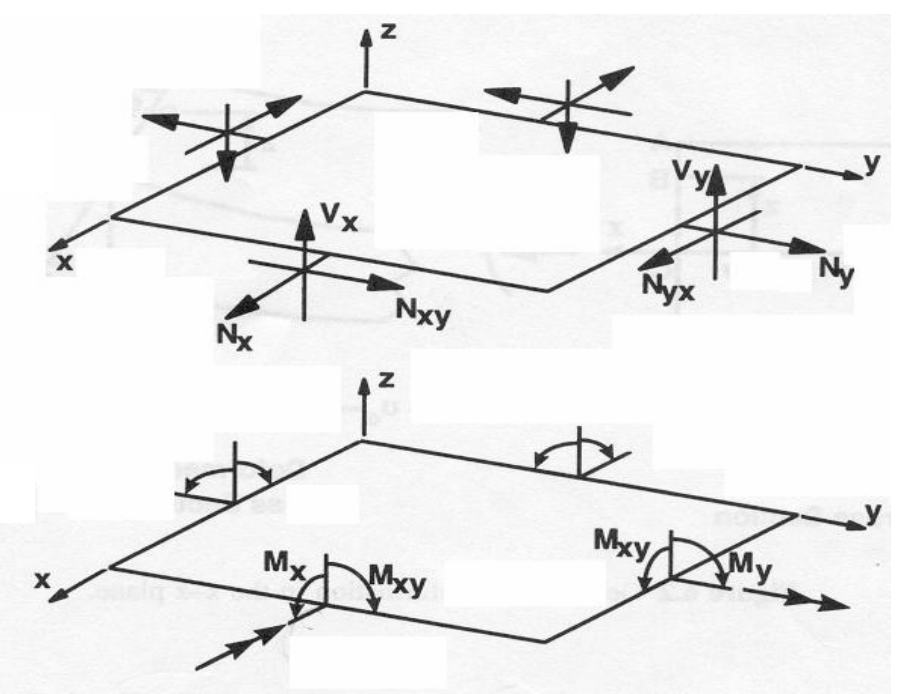

Figure 2.3 In-plane forces and moment resultants (Barbero, 1998)

\subsubsection{Composite Plate Theories}

There are several theories currently in use for the composite laminated plates [Reddy (1997)]. The simplest one, the classical laminated plate theory (CLPT) is based on following assumptions.

1) The transverse normals before deformation remain straight after deformation also.

2) The transverse normals do not experience any elongation $\left(\varepsilon_{z z}=0\right)$.

3) The transverse normals rotate such that they remain perpendicular to the mid-surface after deformation. $\left(\varepsilon_{x z}=0\right.$ and $\left.\varepsilon_{y z}=0\right)$.

4) The laminates are bonded perfectly.

5) The top and bottom surfaces of the plate do not experience any transverse shear stresses.

Composites have a very low transverse shear modulus compared to their in-plane moduli. Therefore, the CLPT may not be sufficient for the dynamic analysis of composite plates. To account for the shear deformation, the first order shear deformation theory (FSDT) can be adopted for the analysis. The FSDT assumes that the transverse normals 
are straight but not perpendicular to the mid surface after deformation. Thus transverse shear strains are constant through the cross section. Since the actual shear stress is not constant, FSDT uses a shear correction factor. For plates and beams of rectangular cross section, the shear correction factor is $5 / 6$. The third order theory is also based on the same assumptions as that of FSDT, except that the assumption on the straightness of the transverse normal after deformation is relaxed. The transverse normal is no longer inextensible, making the deformations as a function of the thickness coordinate. Figure 2.4 shows the deformation of transverse normals for CLPT, FSDT and HSDT.

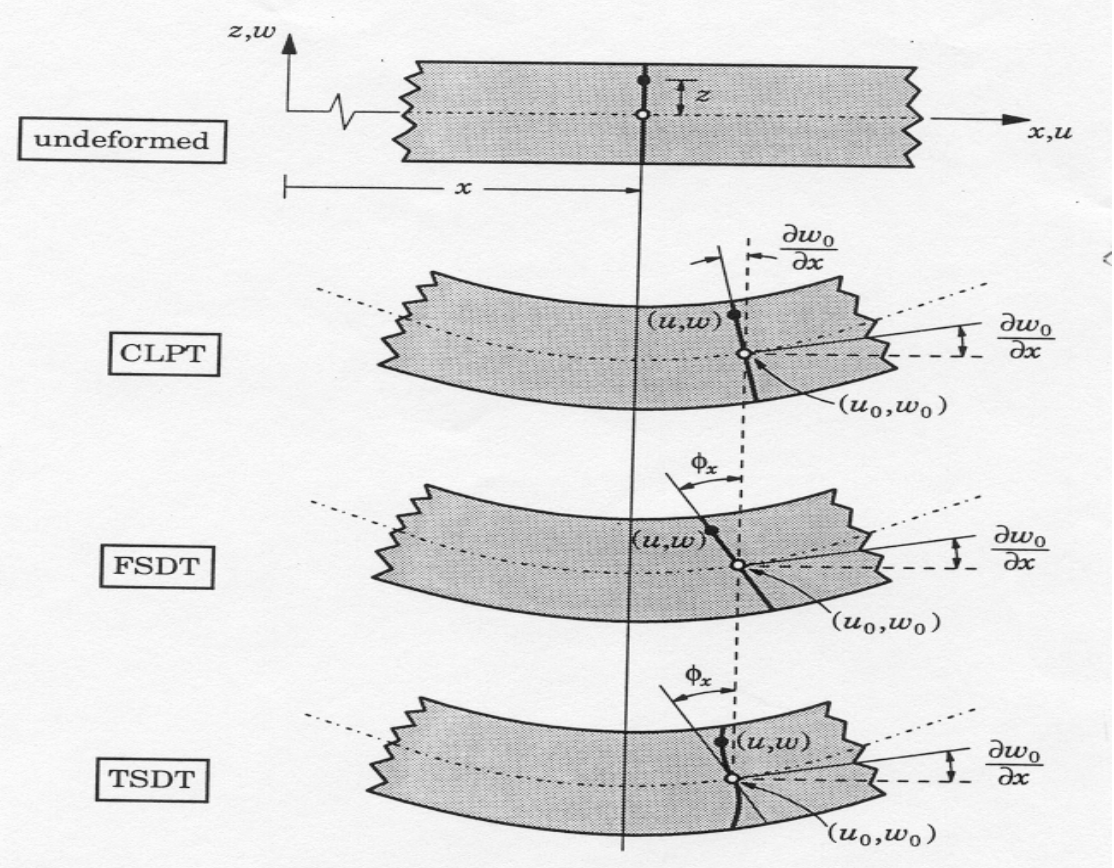

Figure 2.4 Deformation of transverse normal for CLPT, FSDT and HSDT [Reddy (1997)]

\subsection{Hygrothermal Analysis}

The use of fiber reinforced matrix composites in engineering applications has been tremendously increasing. Therefore, it is very important to study the response of 
these materials to environmental conditions like temperature and moisture. The performance of these materials degrades as a result of hygrothermal exposure. Due to moisture and temperature exposure, properties such as the stiffness, strength, life, modulus and conductivities of a composite material decrease considerably. Therefore, experimental and analytical methods have to be carried out to study their responses.

Shen and Springer (1976) have defined maximum moisture content $\left(M_{m}\right)$ as the moisture level reached in a material when exposed to long periods of a constant temperature and moisture environment. The maximum moisture content of a material exposed to humid air can be approximated by the equation given by Springer, $M_{m}=a \varnothing^{b}$, where $\varnothing$ is relative humidity, and $a$ and $b$ are constants. In reality, the moisture content greatly depends on temperature. The glass transition temperature $\left(T_{g}\right)$ is defined as the temperature at which the glassy form of a polymer changes to rubbery form.

Prolonged exposure to a hygrothermal environment has two major effects on a polymer matrix composite structure. The first one is of a residual nature. The coefficient of thermal expansion is usually higher for the matrix. Polymers absorb moisture readily whereas fibers are hardly affected by a wet environment. Further the absorption of moisture by the matrix is more pronounced at higher temperatures. An increase in the ambient temperature and/or humidity level causes the matrix to expand; contrarily, reduced temperature and/or moisture level of the surrounding environment results in a contraction of the matrix. Since the fibers are relatively immune to changes in temperature and moisture content, the differential expansion/contraction leads to residual stresses in a PMC lamina. A comparable phenomenon takes place at the laminate level due to the anisotropic nature of the laminate coefficient of thermal expansion and 
coefficient of hygroscopic expansion. These residual stresses may starkly reduce the load carrying capacity of a structure made of a polymer matrix composite. Upadhyay and Lyons (2000 a) consider the effect of hygrothermal residual stresses on the large deflection of plates.

The second significant effect of an increased hygrothermal condition is the degradation of the mechanical properties of a PMC ply. Again it is the matrix that bears the brunt of this degradation while the fiber properties remain nearly unchanged. The degradation occurs in both the stiffness and strength values of the matrix and consequently in the corresponding values of the lamina. In the present research only this degradation effect is considered while ignoring the residual stresses.

It is observed from various studies conducted by Shen and Springer $(1976,1977)$ that the exposure to high moisture and temperature do not significantly affect the fiber related properties, but, the matrix properties get affected considerably. Therefore, the loss in performance can be related to temperature and moisture content of the matrix material. In this study, the relations given by Chamis (1983) are used to calculate the degraded properties of composite due to hygrothermal conditions. It is assumed that only matrix properties are affected by the raise in temperature and moisture content. According to Chamis, the relationship between the wet resin and dry resin mechanical properties can be stated as

$$
\frac{\mathrm{P}_{H T M}}{\mathrm{P}_{0}}=\left[\frac{\mathrm{T}_{g w r}-\mathrm{T}}{\mathrm{T}_{g d r}-\mathrm{T}_{0}}\right]^{0.5}
$$

where $P$ is the property to be measured, HTM stands for hygrothermal mechanical, $T_{\mathrm{gwr}}$ is glass transition temperature of wet resin and $T_{g d r}$ is the glass transition temperature of 
dry resin. $T$ is the temperature at which property to be measured and $T_{0}$ is the room temperature. This is a steady state equation that relates the properties of the matrix for dry and wet conditions at particular values of moisture content and temperature.

The relation between $T_{g w r}$ and $T_{g d r}$ in terms of moisture content is given by Chamis and is stated as

$$
T_{g w r}=\left(0.005 m^{2}-0.1 m+1.0\right) T_{g d r}
$$

where $m$ is the moisture content expressed in weight percent $(m \leq 10 \%)$.

By using the rule of mixtures and changed properties of the matrix, elastic constants of the composite are calculated. According to the rule of mixtures, the values of longitudinal modulus, $E_{1}$, transverse modulus, $E_{2}$, and in plane shear modulus, $G_{12}$, are calculated as follows:

$$
\begin{aligned}
& E_{1}=E_{f} V_{f}+E_{m} V_{m} \\
& E_{2}=\frac{E_{m} E_{f}}{E_{f} V_{f}+E_{m} V_{m}} \\
& G_{12}=\frac{G_{m}}{V_{m}+G_{m} V_{f} / G_{f}}
\end{aligned}
$$

where $E_{f}, E_{m}, V_{f}, V_{m}, G_{f}$, and $G_{m}$ are modulus of elasticity of fiber, modulus of elasticity of matrix, fiber volume fraction, matrix volume fraction, fiber in plane modulus and matrix in plane modulus, respectively.

\subsection{Governing Equations for Cylindrical Bending of Plates}

Cylindrical bending of plates is considered to validate the hygrothermal approach. Figures 2.5 and 2.6 shows a laminate of length $L$, thickness $h$ subjected to in-plane tensile load $N_{x}$ and uniform transverse load $q$, respectively. The equations 2.6, 2.7 and 2.8 are 
referred from Upadhyay and Lyons (2000) and are formulated for transverse and in-plane loadings for pinned-pinned and clamped-clamped boundary conditions.

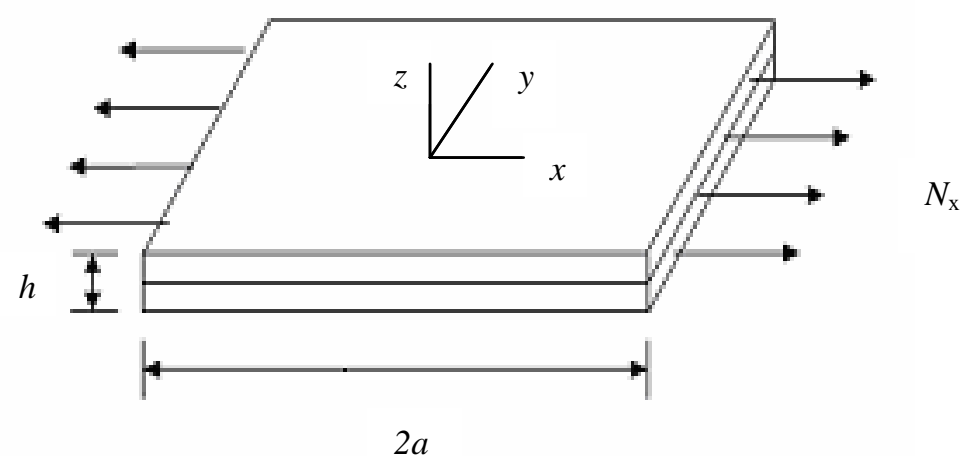

Figure 2.5 Laminate subjected to tensile in-plane load, $N_{x}$

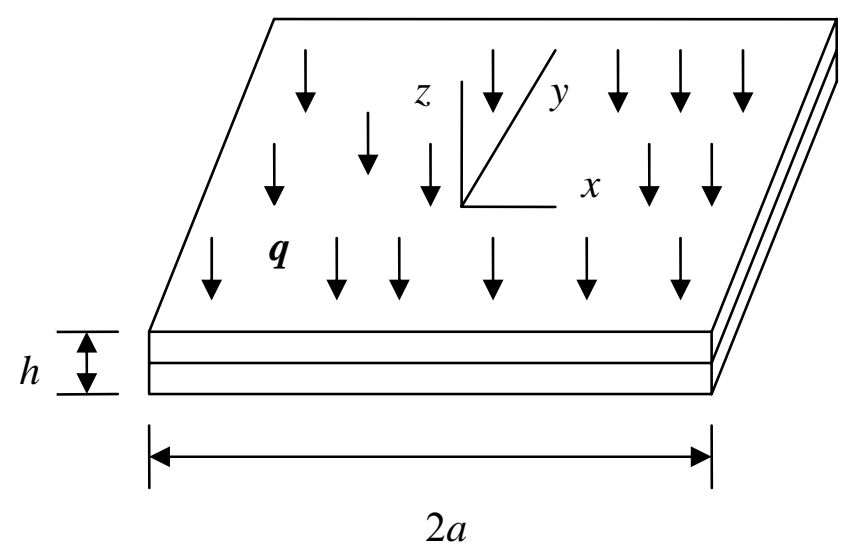

Figure 2.6 Laminate subjected to uniform transverse load, $q$

For an asymmetric cross-plied laminate subjected to only in-plane loading $(q=0)$ and with simply supported boundary conditions along its edges $(x= \pm a)$. According to classical linear theory, the equation for transverse deflection $w(x)$ is written as, 
$w(x)=\frac{1}{2} \frac{B_{11} N_{x}}{\left(D_{11} A_{11}-B^{2}{ }_{11}\right)}\left(x^{2}-a^{2}\right)$

where $A_{11}, B_{11}$, and $D_{11}$ are in-plane stiffness, extension-bending coupling coefficient and bending stiffness of the laminate, respectively.

Consider a laminate with coordinate axis at the mid-plane and $z$ axis normal to the mid-plane. The laminate is simply supported at the edges $x= \pm a$. The bending moment and the in-plane displacement are zero at $x= \pm a$. For a uniform transverse loading, the classical linear theory yields the transverse deflection as,

$w(x)=\frac{q_{0}}{24}\left(x^{4}-a^{4}\right)-\left\{\frac{3 D_{11} A_{11}-2 B_{11}^{2}}{12 D_{11} A_{11}}\right\} q_{0} a^{2}\left(x^{2}-a^{2}\right)$

Similarly, the transverse deflection of a clamped laminate subjected to transverse load can be stated as,

$w(x)=\frac{q_{0} a^{2}}{24}\left(a^{2}-2 x^{2}\right)+\frac{q_{0} x^{4}}{24}$ 


\section{FINITE ELEMENT MODELING}

\subsection{Introduction}

The finite element analysis is a computer assisted numerical technique useful in solving for the response of a structure subjected to loading. In this technique, a mathematical/computer model of the structure is created and analyzed for deformations and stresses. The model is divided into small blocks called elements. These elements are connected by nodes at which the finite element boundary conditions are applied. A set of algebraic equations are created for each element and combined simultaneous equations are solved. A post processor to the finite element program may be helpful in displaying the stresses and deflections in the form of contours for easy comprehension. A number of finite element packages are available for the analysis of complex structures under various types of loads. A finite element package is chosen depending on the complexity of the model and the results needed.

\subsection{Overview of ANSYS}

The ANSYS is a versatile finite element package which can be used to analyze structural, thermal, electrical, and contact problems. The ANSYS graphical user interface (GUI) is divided into three modules, namely, preprocessor (/PREP7), solution (/SOLU) and post processor (/POST1). The preprocessor step consists of selecting the proper elements, providing real constants, material properties, and meshing the model; loads and displacement boundary conditions can also be applied in this module. Alternatively, the boundary conditions may be applied in the solution module, whose primary role is to solve for the desired quantities. The results of the solution are displayed using the general 
post processor. Contour plots of stresses, deformations, nodal solution, and element solution can be carried out in this module.

The ANSYS solution module provides for a number of options such as static, transient, harmonic, modal, buckling and sub structuring analyses. In this thesis, only static, modal and transient analyses are carried out.

\subsubsection{Modeling in ANSYS of the present problem}

As noted earlier, the preprocessor is used to define suitable elements, real constants for those elements, material properties and to model the geometry. In the present analysis, Beam3, a two-dimensional beam element is used to model the isotropic beam. At each node, this beam has three degrees of freedom, namely, UX, UY and ROTZ. This is a uniaxial element which can account for axial and bending deformations. The beam is defined by two nodes, I and J, area of cross section, moment of inertia and beam height. As shown in figure 3.1, in the present study, the beam is modeled with twenty elements, simply supported at the two ends. At one end, the beam is constrained in the global $X$ and $Y$ directions and at the other end it is restricted only in the global $Y$ direction. The material properties of the beam are entered in the form of modulus of rigidity, Poisson's ratio and density. Figure 3.2 describes the nodal coordinates of the BEAM 3 element.

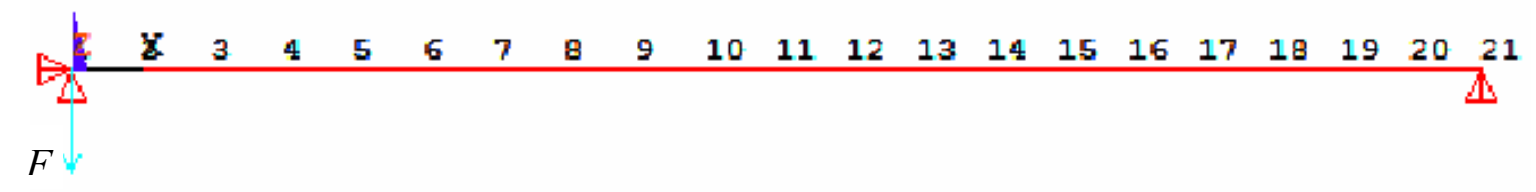

Figure 3.1 Simply Supported beam subjected to a moving load 


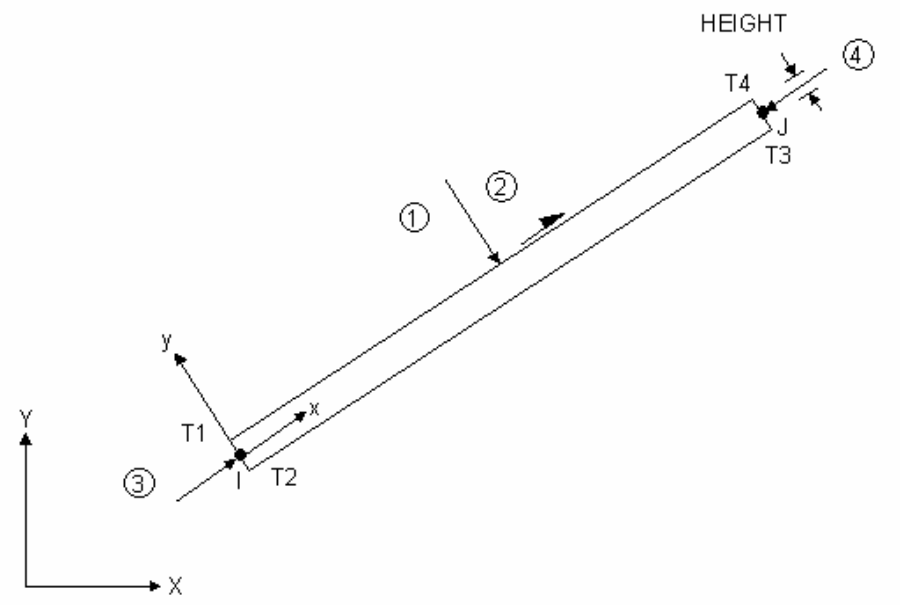

Figure 3.2 Beam3, 2-D Elastic Beam (ANSYS 7.0 Documentation)

Modeling of a beam made of composite materials is a more difficult task. Special attention has to be paid in defining the material properties, orientations of the layers and the element coordinate systems. For the transient analysis of a composite beam under a moving load, the Solid 191 element is used in this study. The Shell99 element is used for the analysis of asymmetric composite laminates under dry and wet conditions. The Solid191 element is a twenty-node layered structural solid element. This element has three degrees of freedom at each node, namely, translation in the $X, Y, Z$ directions. This element can take a maximum of 100 layers and a user input option is available if more than 100 layers have to be modeled. An alternative type of element, the Shell element can be used to model composite beams. Unlike shell elements, solid elements can account for interlaminar shear stresses. Figure 3.3 shows description of a Solid 191 element. 


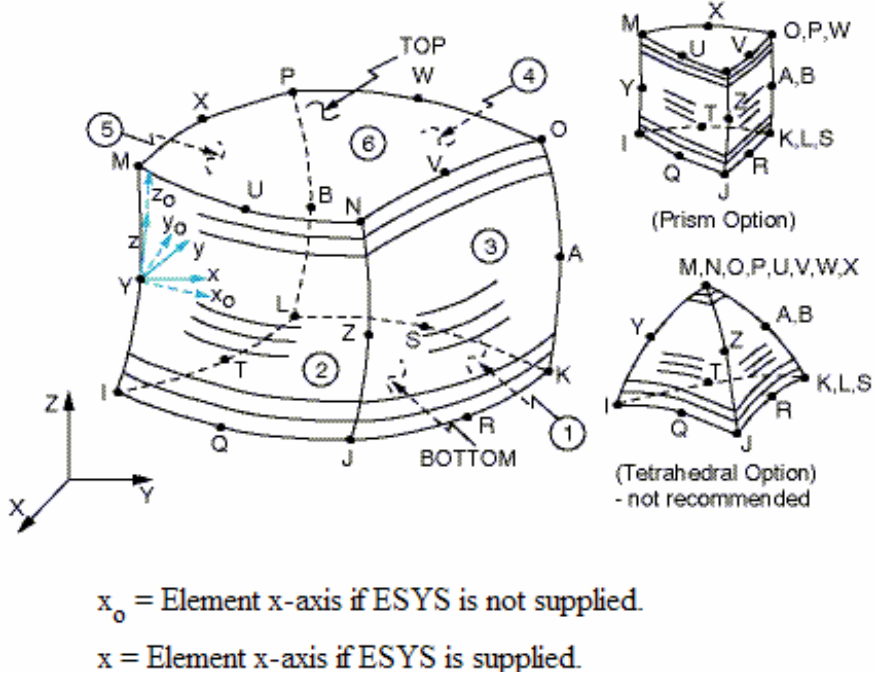

Figure 3.3 Solid 191 Element (ANSYS 7.0 Documentation)

For, side-to-thickness ratio of ten or greater, the Shell99 element can be used. The Shell99 is an eight noded 3- D shell element that can take maximum of 250 equal thickness layers. This element has six degrees of freedom at each node.

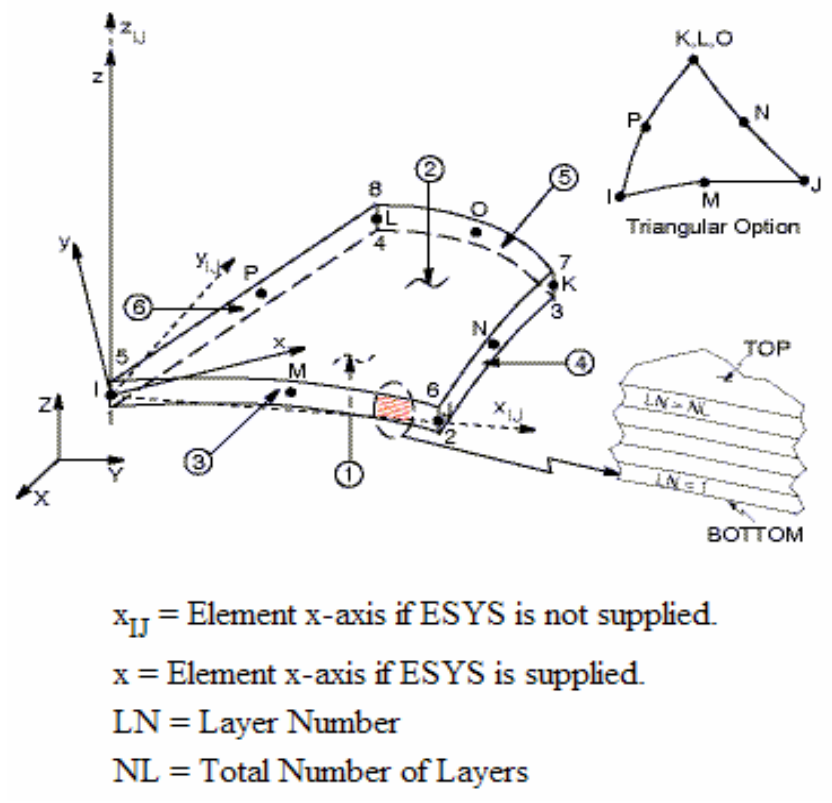

Figure 3.4 Shell 99 Element (ANSYS 7.0 Documentation) 
Figure 3.3 illustrates the typical configuration of the Shell99 element. The global and element coordinate systems are explained in this figure. Mid side nodes cannot be removed from this element. A triangular element can be formed by defining the same node numbers for three nodes as shown in the same figure. In this thesis work, Beam 3 element is used to model isotropic beam, whereas, Solid191 and Shell 99 elements are used to model the composite materials.

\subsection{Boundary Conditions and Meshing}

Boundary Conditions are the constraints and loads that can simulate the effect of the environment surrounding a body. Loads are applied in the form of forces, moments, pressures, and temperatures. The displacement constraints are applied by restricting the degrees of freedom at the corresponding nodes of a model. The proper specification of the boundary conditions is critical in a finite element analysis. Since, improper application of boundary conditions can create problems such as increased stiffness, rigid body motion, and high local stresses. In the present research, simply supported and clamped-clamped beams are used for analysis.

\subsubsection{Meshing}

Meshing is the process of dividing the model into elements, which are connected by nodes at the element boundaries. Meshing is one of the important steps in successfully performing a finite element analysis. The type and density of the mesh determines the economy and accuracy of the solution. Therefore, an analyst should use valid assumptions in determining the exact meshing parameters. A coarse mesh can lead 
to inaccurate solutions and a very fine mesh may increase the time of analysis. In order to define a suitable mesh, an analyst should have an idea of the parameter distributions within the model. Also a convergence study needs to be carried out by increasing the number of elements.

Meshing can be done in two ways, free and map meshing. In free meshing, the elements that are created are of no definite shape and pattern. In contrast to this, a mapped mesh produces a definite element shape and follows a particular pattern.

\subsection{Modal Analysis}

The main objective of any modal analysis is to make sure the structure is not subject to resonant frequency under the range of operation. Natural frequency is the frequency at which the structure vibrates if the forcing function is identically zero. The lowest natural frequency is often referred to as the fundamental frequency, which is the most important parameter for design engineers as many of the systems are designed to operate below it.

The ANSYS has several mode extraction methods such as subspace, block Lanczos, power dynamics, reduced, unsymmetric, and damped. Each method has its own advantages and disadvantages. The method that is used in the present work is the subspace method of mode extraction. Modal analysis is the preliminary step of a dynamic transient analysis. The important thing about a modal analysis is that it ignores any nonlinearity present in the model. 


\subsubsection{Subspace method of mode extraction}

This method of modal analysis is used when the number of modes that are to be extracted is less than 40 . This method works better when the models have a definite shape of solid and shell elements. The modal analysis is nothing but the eigenvalue problem:

$[K]\left\{\varphi_{i}\right\}=\omega_{i}^{2}[M]\left\{\varphi_{i}\right\}$

where $[K]$ is stiffness matrix, $\left\{\varphi_{i}\right\}$ is mode shape vector of mode $\mathrm{i}, \omega_{i}$ is the natural circular frequency, $\omega_{i}^{2}$ is the eigenvalue and $[M]$ is the mass matrix.

The Subspace method is an iterative technique that makes use of Jacobi iterative algorithm. This is considered as a highly accurate method since it uses the full $[K]$ and $[M]$ matrices.

In the present work, a maximum of five mode shapes are extracted, but the point of interest is only the fundamental period of the beams. The fundamental period of the beam is the inverse of the first natural frequency. In the present research, modal analysis is the preliminary step in a transient dynamic analysis.

\subsection{Transient Dynamic Analysis}

This type of analysis is also known as time-history analysis. This method is generally used to determine response due to time varying loads. Through this analysis, we can find the time varying stresses, strains, and deflections produced when a system responds to the transient loads. A transient analysis is more complex and time consuming method compared to a static analysis, as it requires more engineering input data and better understanding of the system response. An analyst must have a good insight of the problem involved in the analysis. 
There are three methods present in ANSYS to solve dynamic problems: full, reduced, and mode superposition. In this present work, the full transient analysis is used to solve the moving load problem. The ANSYS uses the Newmark method for time integration. The transient analysis can be treated as static analysis solved at discrete time steps. 


\section{RESULTS AND DISCUSSIONS}

\subsection{Introduction}

This chapter describes the results obtained from the finite element analysis using ANSYS. Model validation is achieved by comparisons with analytical results and results available in literature. Results from three broad categories of analysis are presented. The first one deals with dynamic deflection factors of isotropic and laminated composite beams under different moving load velocities. The aim of this part of the analysis is to validate the moving load modeling. The second is that of in plane and transverse deflections of laminated composite plates under cylindrical bending and subjected to hygrothermal conditions. The third set consists of a parametric study on laminated composite beams subjected to moving loads in a hygrothermal environment, wherein new results are presented. This second part validates the modeling of hygrothermal effects.

\subsection{Isotropic Beam Comparison}

The dynamic deflection factor of an isotropic simply-supported steel beam under a moving load is evaluated using ANSYS. The dynamic magnification factor is the ratio of the maximum magnitude of the dynamic deflection at the mid-span of beam to the static deflection at the same location. First, a static analysis of the beam on ANSYS is done by applying a load at the center to get the maximum static deflection of the beam. The geometric and material properties of the beam used by Kadivar and Mohebpour (1997) are taken to simulate the model. The length, width, and thickness of the beam are 4 in., 0.25 in., and 0.25 in., respectively. The beam has a modulus of elasticity, $E=30 \times 10^{6} \mathrm{psi}$,

and with a fundamental period, $T_{f}=8.149 \times 10^{-4} \mathrm{~s}$. A moving force of magnitude $1 \mathrm{lb}$ is 
applied on this simply supported beam. Initially the load is applied at the left end of the beam and then the load moves toward the right end with a velocity, $V$.

\subsubsection{Static Central Deflection of Simply Supported Isotropic Beam}

The static deflection at the mid span of a simply supported beam can be calculated analytically as

$$
\delta_{s}=\frac{P L^{3}}{48 E I}
$$

where $P$ is the static vertical load applied at the center of the beam, $L$ is the length of the beam, $E$ the modulus of elasticity and $I$ the moment of inertia.

The finite element model of the beam is modeled in ANSYS using 2D beam elements, namely Beam3. The value of $P$ is taken to be $1 \mathrm{lb}$. The mid-span deflection of the finite element model in ANSYS is compared with the analytical result from Eq. (4.1) in Table 4.1 and they are in excellent agreement.

Table 4.1 Static mid span deflection of a simply supported beam

\begin{tabular}{|c|c|}
\hline Analytical Result & ANSYS Result \\
\hline $1.36614 \times 10^{-4}$ in & $1.36601 \times 10^{-4}$ in \\
\hline
\end{tabular}

\subsubsection{Moving Force on a Simply Supported Isotropic Beam}

A moving force of magnitude $1 \mathrm{lb}$ is applied to a simply supported beam with the same properties as the previous example. As with the static case the beam is modeled in ANSYS using Beam3 elements. A transient dynamic analysis is carried out in ANSYS to move the load from one node to the next node. Twenty time steps are used to simulate the moving load from the left end to the right end of the beam. The time taken by the moving 
load to travel from one end to the other is represented by $T$. The fundamental period of the beam is represented by $T_{f}$. Let $V_{f}$ be the velocity of a reference load that would take a time of $T_{f}$ (fundamental period) to traverse the beam of length $L$. Then the velocity ratio $V / V_{f}$ can be expressed as

$$
\frac{V}{V_{f}}=\frac{V}{L} \times \frac{L}{V_{f}}=\frac{T_{f}}{T}
$$

Several velocity values for the moving load are considered. The moving load velocities and the corresponding velocity ratios and time steps are listed in Table 4.2.

Table 4.2 Moving load velocities and time steps

\begin{tabular}{|c|c|c|c|}
\hline \multicolumn{2}{|c|}{ Moving load velocity } & \multicolumn{2}{c|}{$\begin{array}{c}\text { Velocity ratio } \\
T_{f} / T\end{array}$} \\
\cline { 1 - 2 } $\mathrm{ft} / \mathrm{s}$ & $\mathrm{mph}$ & 0.125 & $3.257 \times 10^{-4}$ \\
\hline 51.16 & 34.88 & 0.25 & $1.628 \times 10^{-4}$ \\
\hline 102.33 & 69.77 & 0.5 & $0.814 \times 10^{-4}$ \\
\hline 204.66 & 139.54 & 1 & $0.407 \times 10^{-4}$ \\
\hline 409.41 & 279.15 & 2 & $0.203 \times 10^{-4}$ \\
\hline 820.16 & 559.20 & & \\
\hline
\end{tabular}

A convergence study is performed to decide the number of elements in the model. The beam is divided into 20 elements with the help of convergence study. The left end is constrained in the $x$ and $z$ directions whereas the right end is constrained only in the $z$ direction, thus simulating simply supported boundary conditions. By using the transient analysis option in ANSYS, the point load is moved from one end to the other end. At a time step, the load moves from one node to the next. The maximum central deflection of the beam is found for various moving load velocities and listed in Table 4.3. The dynamic deflection magnification factors from the present analysis are compared with that of Taheri (1987) in Table 4.4 and are in excellent agreement. 
Table 4.3 Maximum center deflection for various moving load velocities

\begin{tabular}{|l|c|c|c|}
\hline$T_{f} / T$ & Velocity (mph) & Velocity (ft/s) & Dynamic Deflection (in.) \\
\hline 0.125 & 34.88 & 51.16 & $1.422 \times 10^{-4}$ \\
\hline 0.25 & 69.77 & 102.33 & $1.481 \times 10^{-4}$ \\
\hline 0.5 & 139.54 & 204.66 & $1.742 \times 10^{-4}$ \\
\hline 1.0 & 209.37 & 307.08 & $2.941 \times 10^{-4}$ \\
\hline 2.0 & 559.20 & 820.16 & $2.054 \times 10^{-4}$ \\
\hline
\end{tabular}

Table 4.4 Dynamic magnification factors for moving force on isotropic beam

\begin{tabular}{|c|c|c|c|c|}
\cline { 3 - 4 } \multicolumn{2}{c}{} & \multicolumn{2}{c|}{ Dynamic magnification factor } \\
\hline$T_{f} / T$ & $\begin{array}{c}\text { Velocity } \\
(\mathrm{mph})\end{array}$ & $\begin{array}{c}\text { Velocity } \\
(\mathrm{ft} / \mathrm{s})\end{array}$ & $\begin{array}{c}\text { Present } \\
\text { Analysis }\end{array}$ & Taheri (1987) \\
\hline 0.125 & 34.88 & 51.16 & 1.042 & 1.042 \\
\hline 0.25 & 69.77 & 102.33 & 1.082 & 1.083 \\
\hline 0.5 & 139.54 & 204.66 & 1.271 & 1.266 \\
\hline 1.0 & 209.37 & 307.08 & 1.671 & 1.662 \\
\hline 2.0 & 559.20 & 820.16 & 1.514 & 1.518 \\
\hline
\end{tabular}

Figure 4.1 shows the dynamic magnification factor of the isotropic beam with respect to the velocity ratio. This plot consists of an undercritical region and an over critical region. As seen from the graph, in the undercritical region the dynamic deflection of the beam increases with increasing velocity of the load. In the overcritical region, the dynamic deflection decreases with increasing velocity of the load. Figures 4.2-4.5 show the dynamic deflection of the center of the beam for moving load velocities of 51.16, 102.33, 204.66, and $820.16 \mathrm{ft} / \mathrm{s}$, respectively. These graphs are obtained from the timehistory processor of ANSYS. It can be observed that the deflection at the mid-span actually becomes positive (upward) toward the end of the traverse of the moving load for the lower velocity cases. 


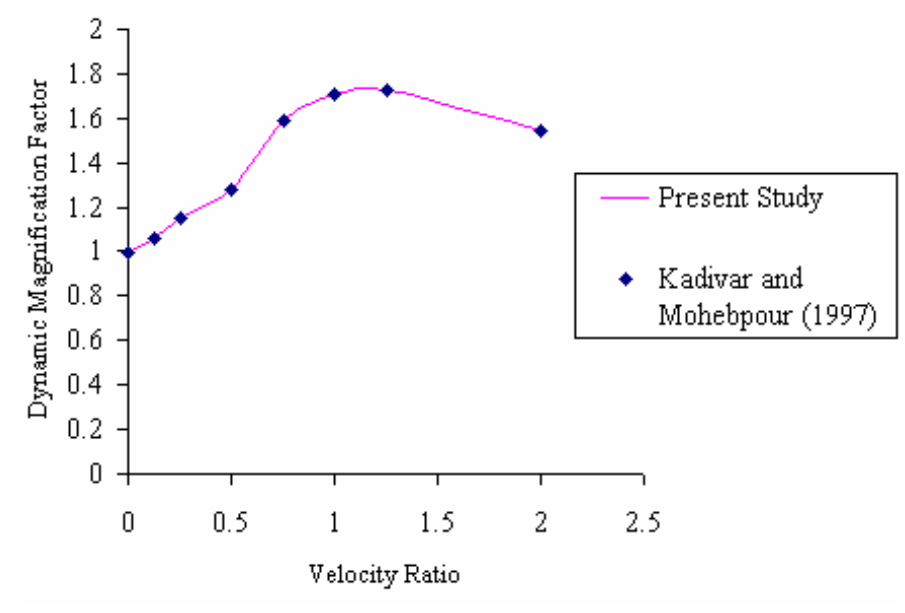

Figure 4.1 Dynamic magnification factor of an isotropic beam

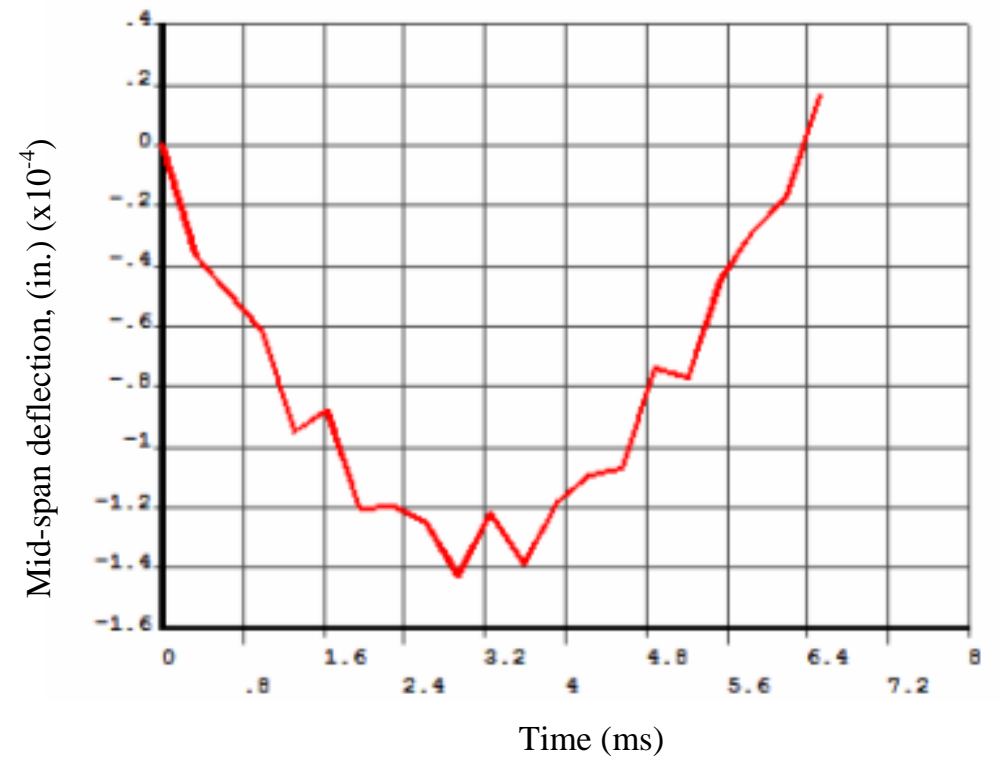

Figure 4.2 Time history of mid-span deflection for $V=51.16 \mathrm{ft} / \mathrm{s}$ 


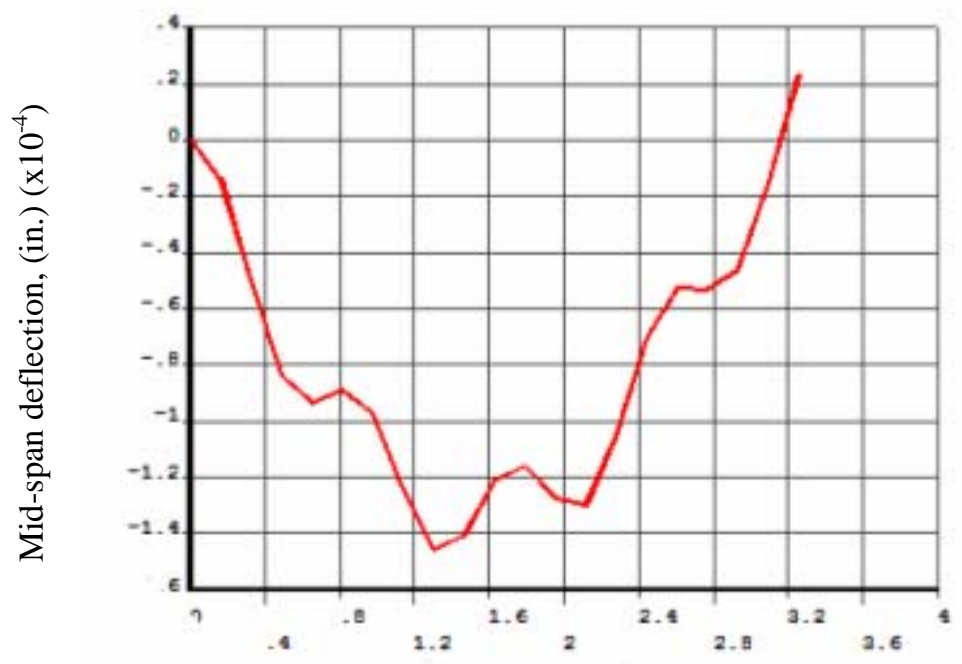

Time (ms)

Figure 4.3 Time history of mid-span deflection for $V=102.33 \mathrm{ft} / \mathrm{s}$

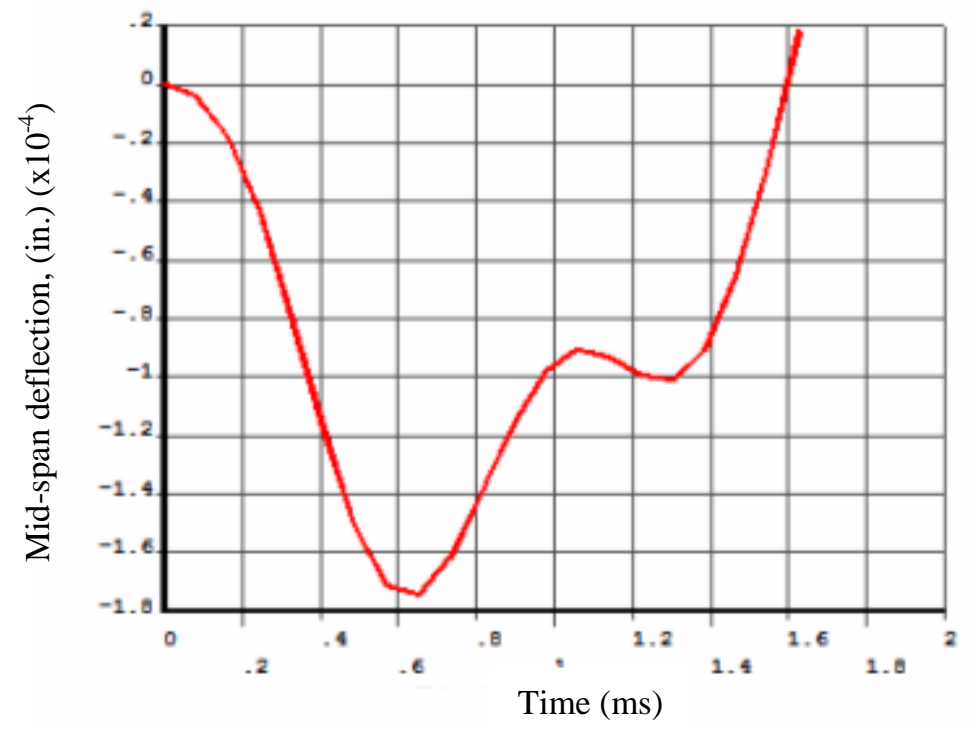

Figure 4.4 Time history of mid-span deflection for $V=204.66 \mathrm{ft} / \mathrm{s}$ 


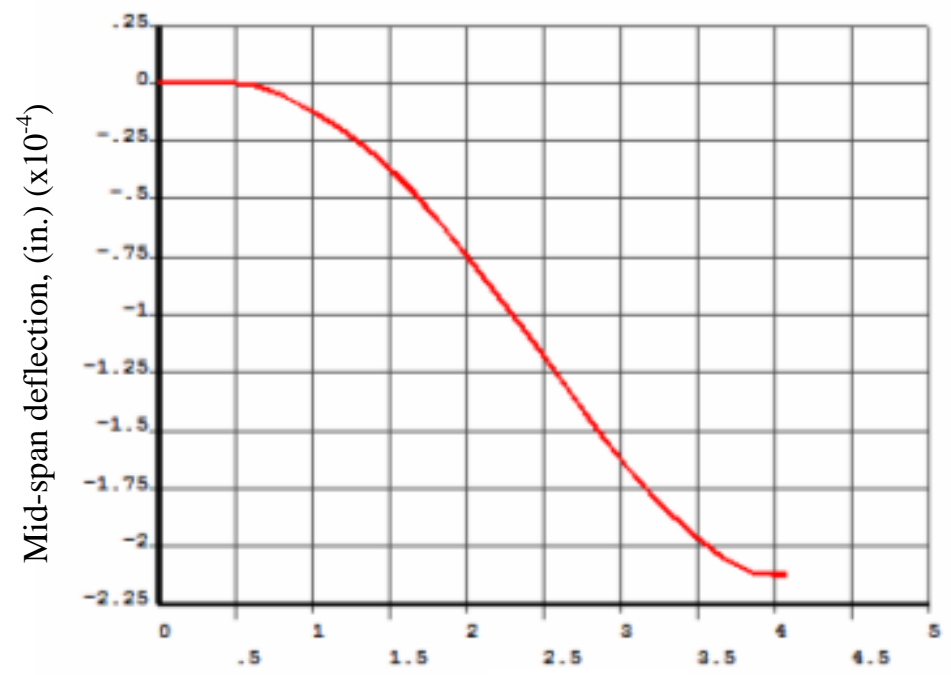

Time (ms)

Figure 4.5 Time history of mid-span deflection for $V=\mathbf{8 2 0 . 1 6} \mathrm{ft} / \mathrm{s}$

\subsection{Composite Beam subjected to Moving Load}

A symmetric cross-ply laminated beam, [0/90]s, made of graphite/epoxy is analyzed next. The geometric and material properties of this model are listed in Table 4.5 .

Table 4.5 Geometric and material properties of composite beam

\begin{tabular}{|l|l|}
\hline \multicolumn{1}{|c|}{ Property } & \multicolumn{1}{c|}{ Value } \\
\hline Beam length, $L$ & 4 in. \\
\hline Beam width, $b$ & $0.25 \mathrm{in}$. \\
\hline Beam height, $h$ & $0.293 \mathrm{in}$. \\
\hline Mass density, $\rho$ & $0.05 \mathrm{lb} / \mathrm{in}^{3}$ \\
\hline Longitudinal Modulus, $E_{1}$ & $21 \times 10^{6} \mathrm{psi}$ \\
\hline Transverse Modulus, $E_{2}$ & $1.4 \times 10^{6} \mathrm{psi}$ \\
\hline Longitudinal Shear Modulus, $G_{12}$ & $0.6 \times 10^{6} \mathrm{psi}$ \\
\hline Inter laminar Shear Modulus, $G_{23}$ & $0.5 \times 10^{6} \mathrm{psi}$ \\
\hline Transverse Shear Modulus, $G_{13}$ & $0.6 \times 10^{6} \mathrm{psi}$ \\
\hline Major in-plane Poisson's ratio, $v_{12}$ & 0.25 \\
\hline Out of plane Poisson's ratio, $v_{23}$ & 0.25 \\
\hline Out of plane Poisson's ratio, $v_{13}$ & 0.25 \\
\hline
\end{tabular}


The beam is meshed using solid 191 elements; there are 20 element divisions along the length of the beam, 4 divisions along the width and 1 division through the thickness. Thus the mesh consists of 80 elements and 621 nodes. A moving load of magnitude $1 \mathrm{lb}$ is applied starting at the left end and traversing the span. The velocities and time steps considered are the same as that for the isotropic case (Table 4.2).

The beam has a fundamental period of $T_{f}=3.187 \times 10^{-4} \mathrm{~s}$. First a static analysis is carried out with a central load of $1 \mathrm{lb}$ and mid-span deflection is found to be $0.000258 \mathrm{in}$. The dynamic magnification factors for various velocities of the moving load are calculated and presented in Table 4.6. The results (FSDT) from Kadivar and Mohebpour (1997) are also included in this table and the comparison indicates excellent agreement.

The dynamic magnification factor as a function of the moving load velocity is plotted in Figure 4.6. Similar to the isotropic beam, this plot contains an undercritical region and a super critical one. The maximum dynamic magnification factor occurs at the velocity ratio of 1.25 , contrary to what one might intuitively expect this to occur at a velocity ratio of 1 . The velocity ratio of 1.25 translates into a velocity of $511.8 \mathrm{ft} / \mathrm{s}$ and this is known as the critical velocity.

The time-history plots of the mid-span deflection for moving load velocities of 51.6, 102.33, 204.66, 307.08, 409.41, 511.75, 820.16 ft/s are shown in Figures 4.7- 4.13. It is seen, as with the isotropic beam, that at higher moving load velocities, the beam has an upward deflection toward the end of the load traverse. This phenomenon is attributed to wave-like motion of the beam in response to the moving load. 
Table 4.6 Dynamic magnification factors for moving load on composite beam

\begin{tabular}{|l|c|c|c|c|}
\cline { 3 - 4 } \multicolumn{2}{c}{} & \multicolumn{2}{c|}{ Dynamic Magnification Factor } \\
\hline$T_{f} / T$ & $\begin{array}{c}\text { Velocity } \\
(\mathrm{ft} / \mathrm{s})\end{array}$ & $\begin{array}{c}\text { Velocity } \\
(\mathrm{mph})\end{array}$ & $\begin{array}{c}\text { Present } \\
\text { Analysis }\end{array}$ & $\begin{array}{c}\text { Kadivar and } \\
\text { Mohebpour (1997) }\end{array}$ \\
\hline 0.125 & 51.16 & 34.88 & 1.063 & 1.063 \\
\hline 0.25 & 102.33 & 69.77 & 1.149 & 1.151 \\
\hline 0.5 & 204.66 & 139.54 & 1.280 & 1.281 \\
\hline 0.75 & 307.08 & 209.37 & 1.586 & 1.586 \\
\hline 1.0 & 409.41 & 279.15 & 1.710 & 1.704 \\
\hline 1.25 & 511.75 & 348.92 & 1.726 & 1.727 \\
\hline 2.0 & 820.16 & 559.20 & 1.542 & 1.542 \\
\hline
\end{tabular}

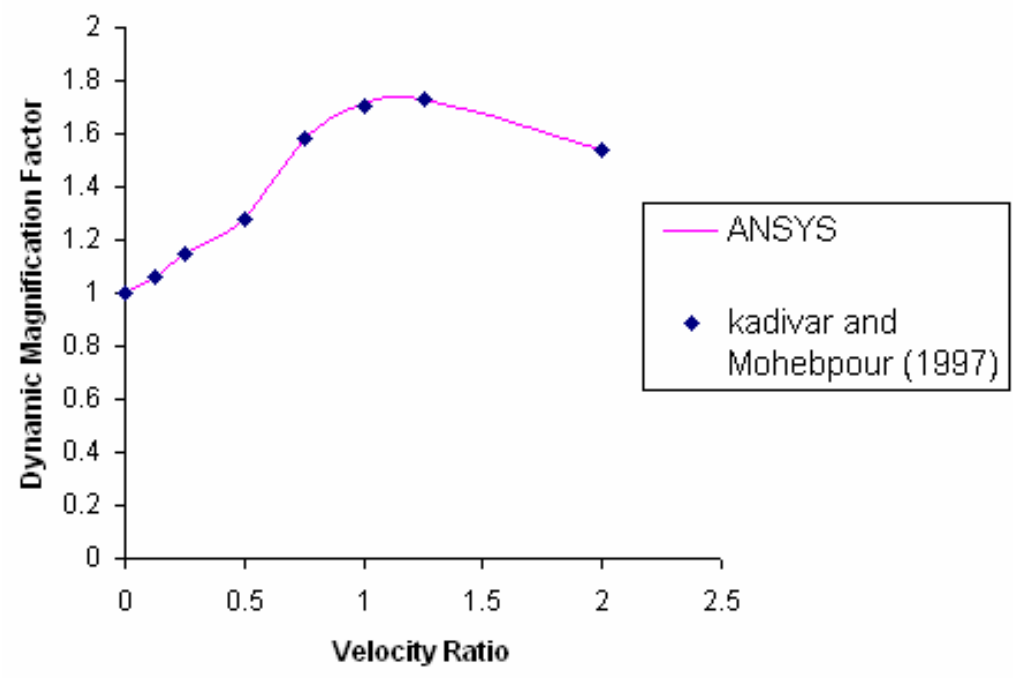

Figure 4.6 Dynamic magnification factors for composite laminated beam 


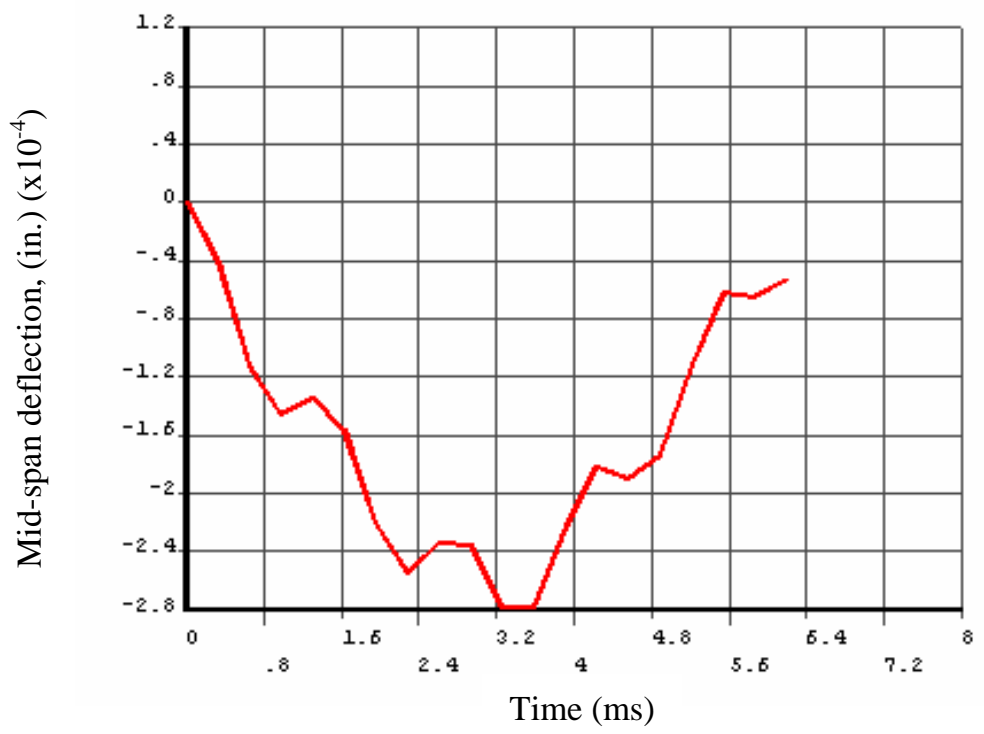

Figure 4.7 Time history of mid-span deflection for $V=51.16 \mathrm{ft} / \mathrm{s}$

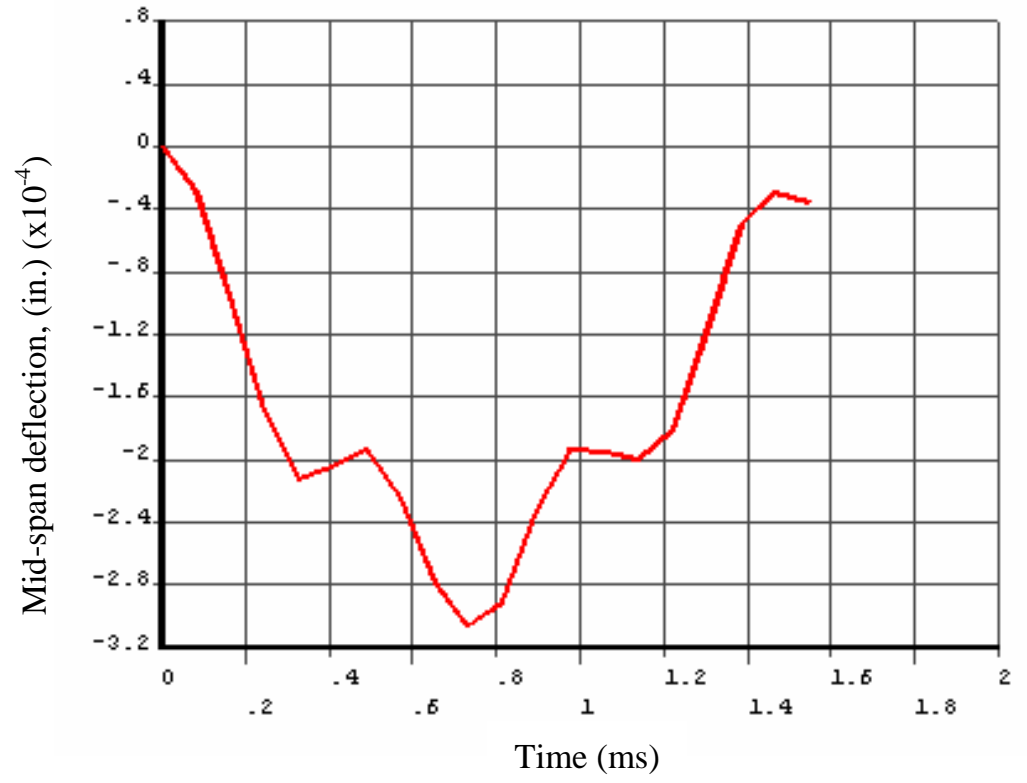

Figure 4.8 Time history of mid-span deflection for $V=102.33 \mathrm{ft} / \mathrm{s}$ 


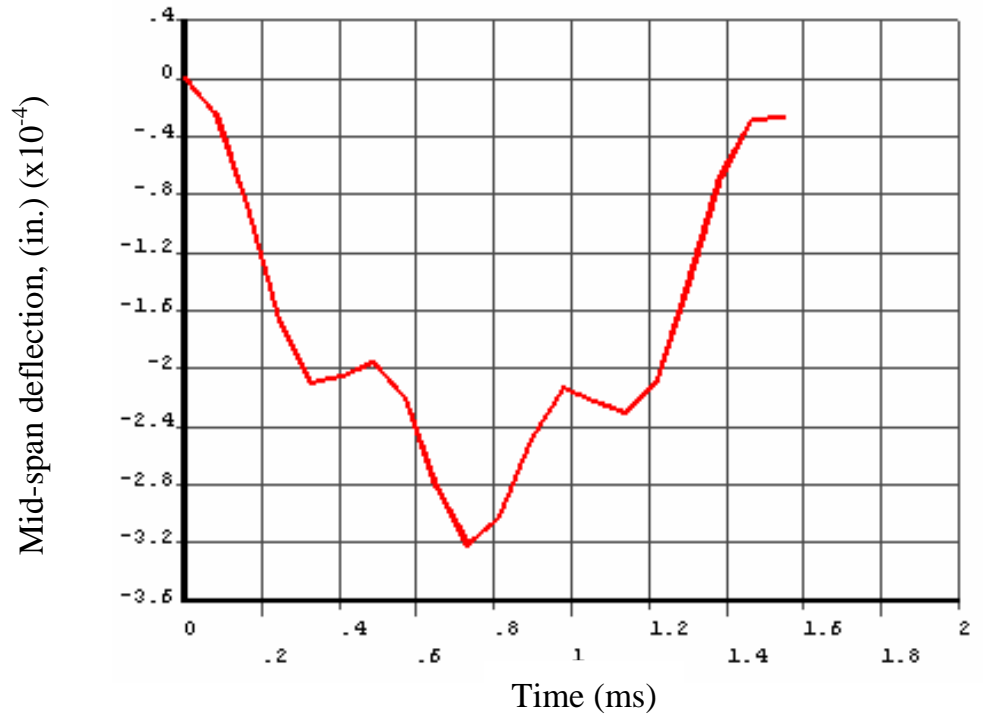

Figure 4.9 Time history of mid-span deflection for $V=204.66 \mathrm{ft} / \mathrm{s}$

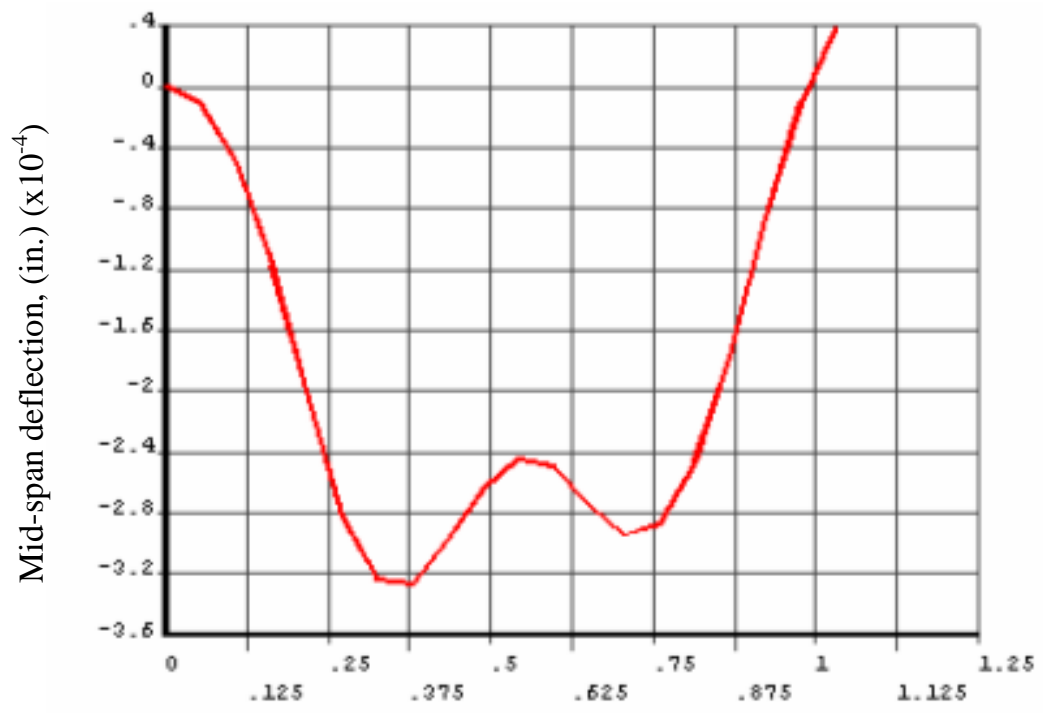

Time (ms)

Figure 4.10 Time history of mid-span deflection for $V=307.08 \mathrm{ft} / \mathrm{s}$ 


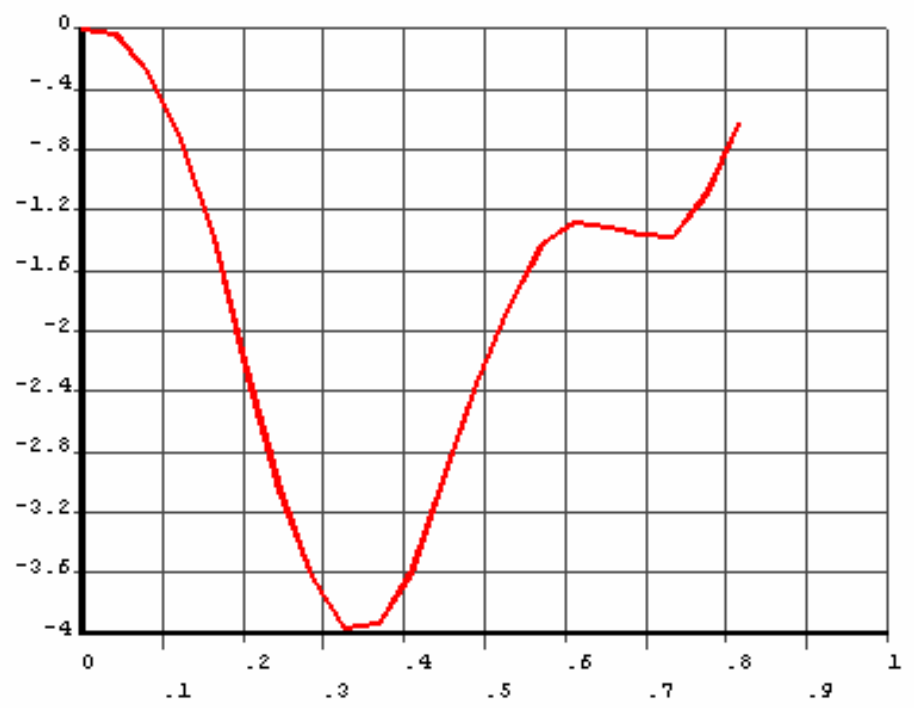

Figure 4.11 Time history of mid-span deflection for $V=409.41 \mathrm{ft} / \mathrm{s}$

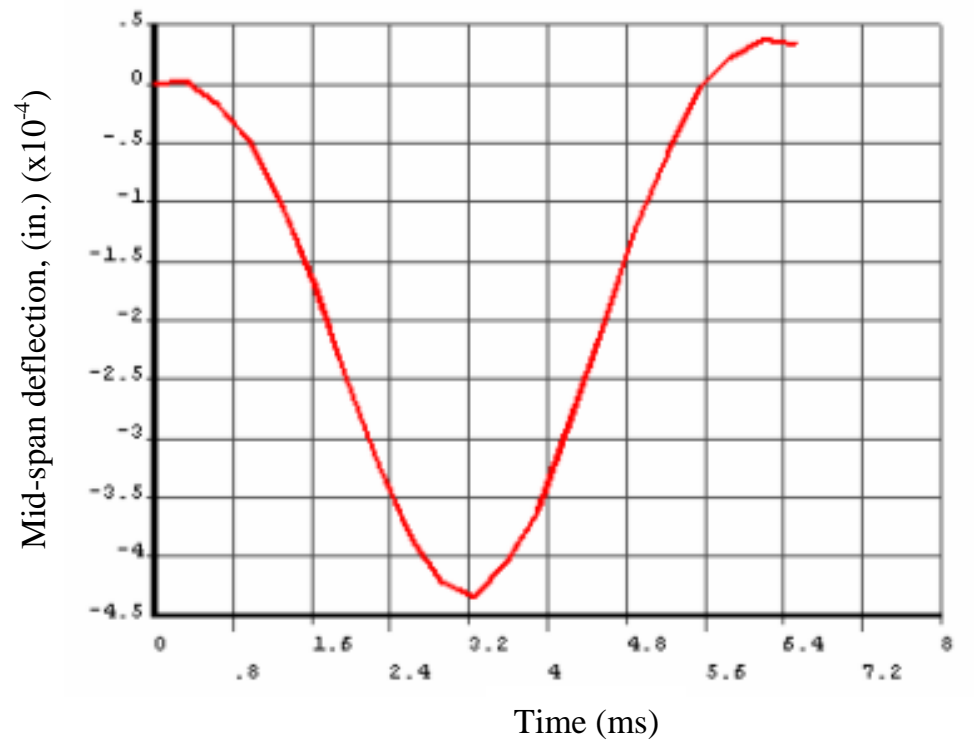

Figure 4.12 Time history of mid-span deflection for $V=511.75 \mathrm{ft} / \mathrm{s}$ 


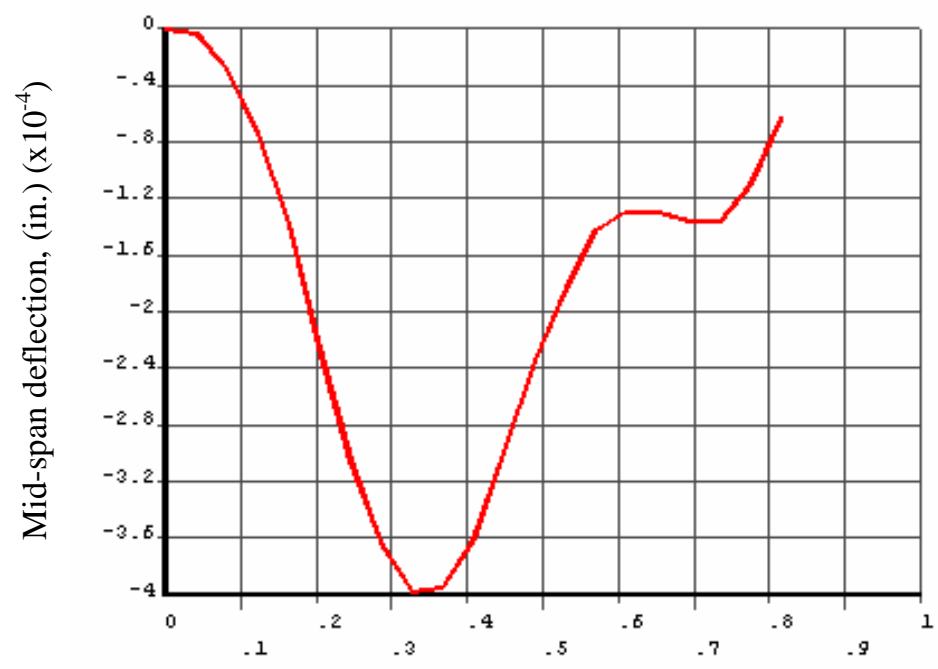

Time (ms)

Figure 4.13 Time history of mid-span deflection for $V=820.16 \mathrm{ft} / \mathrm{s}$

\subsection{Hygrothermal Analysis on Laminated Composite Beams}

In this section, the response of laminated composite beams to hygrothermal conditions is studied to validate the hygrothermal aspect of the model. In this study, the stiffness properties of the constituents are degraded by using the empirical relations (see section 2.3) proposed by Chamis (1983). It is assumed that only matrix properties are affected by temperature change and moisture content. By using the rule of mixtures and changed properties of the matrix, updated elastic constants of the lamina and the laminate are calculated. An asymmetric cross-ply laminate of $\left(04_{4} / 90_{4}\right)$ under cylindrical bending configuration is considered in this study. The length, width and thickness of laminate (see Figure 2.5) are taken as 9 in., 1.5 in., and 0.04 in., respectively. These dimensions are similar to the ones taken by Sun and Chin (1988). S-glass fiber and epoxy composite properties used here are similar to those taken by Cairns and Adams (1984). The results of dry conditions are verified before proceeding to the hygrothermal analysis. The results of various loading and boundary conditions are discussed in the later sections. The 
properties and values of various parameters of the composite are listed in Tables 4.7 and 4.8 .

Table 4.7 Constituent properties of S glass fiber and Epoxy matrix

\begin{tabular}{|l|l|l|}
\hline \multicolumn{1}{|c|}{ Property } & $\begin{array}{c}\text { Owens-Corning } \\
\text { S2 Glass Fiber }\end{array}$ & $\begin{array}{c}\text { Hercules 3501-6 } \\
\text { Epoxy Matrix (Dry) }\end{array}$ \\
\hline Modulus of elasticity, $E$ & $12.5 \times 10^{6} \mathrm{psi}$ & $0.62 \times 10^{6} \mathrm{psi}$ \\
\hline Shear Modulus, $G$ & $5.12 \times 10^{6} \mathrm{psi}$ & $0.23 \times 10^{6} \mathrm{psi}$ \\
\hline Poisson's ratio, $v$ & 0.22 & 0.34 \\
\hline
\end{tabular}

Table 4.8 Parameters in hygrothermal analysis

\begin{tabular}{|l|l|}
\hline \multicolumn{1}{|c|}{ Property } & \multicolumn{1}{c|}{ Value } \\
\hline Moisture Content, $m$ & $5 \%$ \\
\hline Glass transition temperature of dry resin, $T_{g d r}$ & $342^{\circ} \mathrm{F}$ \\
\hline Temperature at which property to be measured, $T$ & $156.2^{\circ} \mathrm{F}$ \\
\hline Temperature at which initial parameter is measured, $T_{0}$ & $70^{\circ} \mathrm{F}$ \\
\hline Glass transition temperature of wet resin, $T_{g w r}$ & $213.75^{\circ} \mathrm{F}$ \\
\hline Fiber Volume Fraction, $V_{f}$ & 0.52 \\
\hline
\end{tabular}

\subsubsection{Dry Conditions}

\subsubsection{Transverse Deflections of Pinned-Pinned Laminate under Uniform Pressure Load}

Pinned-Pinned boundary conditions are applied on the two edges of the composite laminate as shown in Figure 4.14. The laminate is subjected to a uniform transverse load under dry conditions. The temperature and moisture content at dry conditions are taken as $70^{\circ} \mathrm{F}$ and $0 \%$ respectively. Linear static analysis is performed and the transverse deflections are calculated. The results are included in Table 4.9 and Figure 4.15 and show good agreement with the ones obtained by classical linear theory. The deflection along the length of the laminate for the transverse load value of 0.0348 psi is shown in Figure 4.16. It can be observed that the increase in load causes the deflection to increase linearly. 


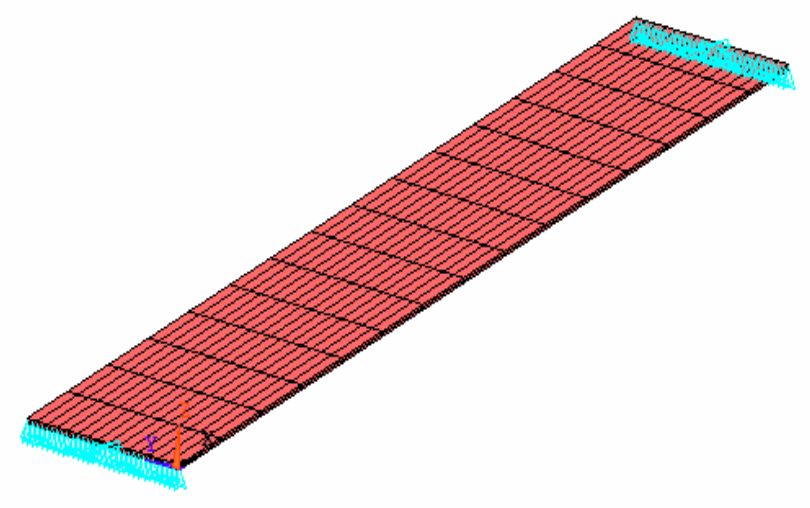

Figure 4.14 Pinned-pinned boundary conditions on composite laminate

Table 4.9 Deflections for pinned-pinned laminate due to uniform transverse load in dry condition

\begin{tabular}{|c|c|c|}
\hline $\begin{array}{c}\text { Transverse Load } \\
\text { (psi) }\end{array}$ & $\begin{array}{c}\text { Transverse deflection (in.) } \\
\text { Present Study }\end{array}$ & $\begin{array}{c}\text { Transverse Deflection (in.) } \\
\text { Linear Theory }\end{array}$ \\
\hline 0.0058 & 0.0249 & 0.025 \\
\hline 0.0116 & 0.0481 & 0.048 \\
\hline 0.0174 & 0.0720 & 0.072 \\
\hline 0.0231 & 0.0963 & 0.096 \\
\hline 0.0292 & 0.0124 & 0.120 \\
\hline 0.0348 & 0.1444 & 0.140 \\
\hline 0.0406 & 0.1680 & 0.160 \\
\hline 0.0464 & 0.9260 & 0.190 \\
\hline 0.0522 & 0.2160 & 0.216 \\
\hline 0.0581 & 0.2407 & 0.241 \\
\hline
\end{tabular}




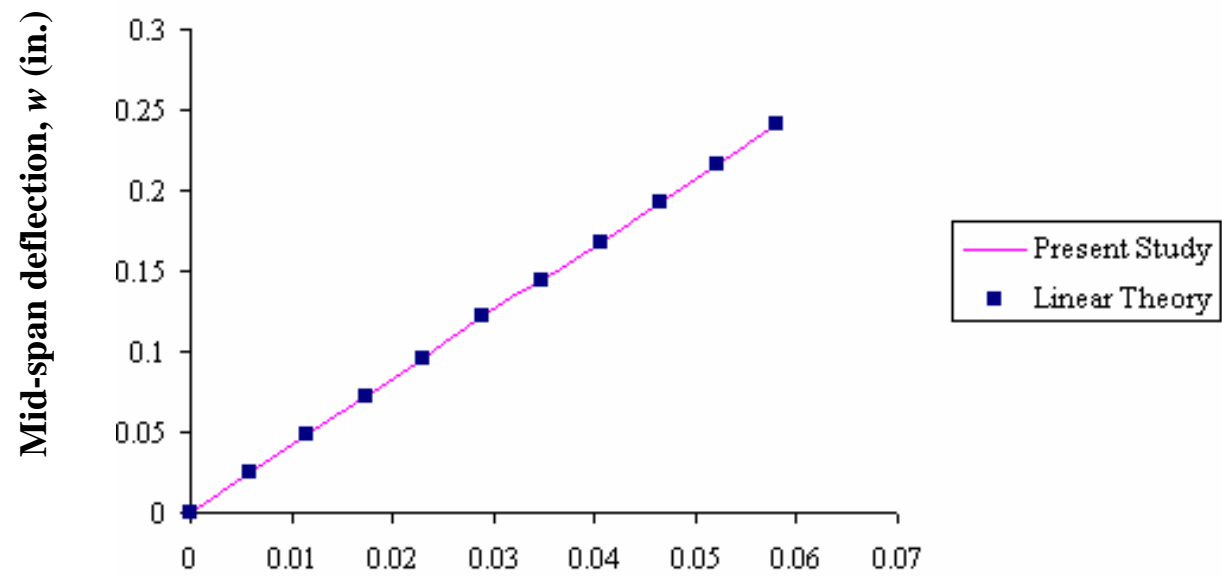

Uniform transverse load (psi)

Figure 4.15 Deflections for pinned-pinned laminate for uniform transverse load in dry condition

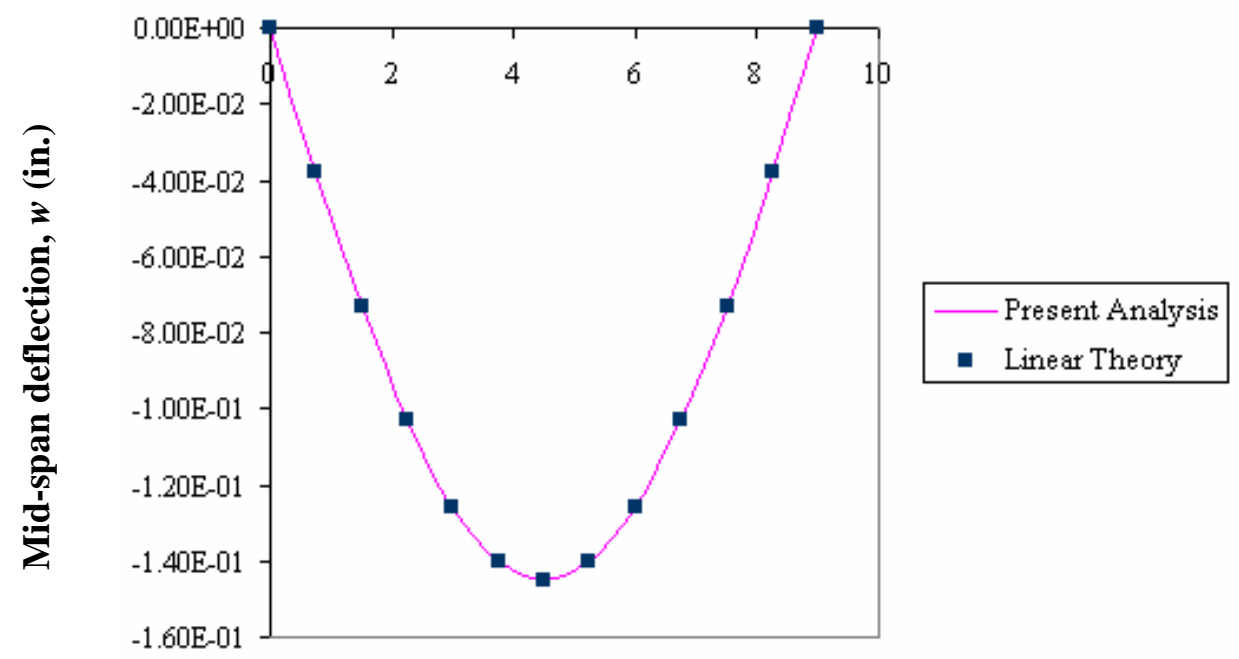

Longitudinal coordinate, $x$ (in.)

Figure 4.16 Transverse deflection distribution for 0.0348 psi 


\subsubsection{Transverse Deflections of Clamped-Clamped Laminate under Uniform}

\section{Transverse Load}

In this section, the boundary conditions of the laminate are changed to clampedclamped. The outer edges of the laminate are clamped and a uniform load is applied on the beam. Linear static analysis is carried out and the transverse deflections are calculated. The results are included in Table 4.10 and Figure 4.17. The deflection along the length of the laminate for the transverse load value of 0.0363 psi is shown in Figure 4.18.

Table 4.10 Transverse deflections for clamped-clamped laminate due to uniform transverse load in dry condition

\begin{tabular}{|c|c|c|}
\hline $\begin{array}{l}\text { Pressure Load } \\
\text { (psi) }\end{array}$ & $\begin{array}{c}\text { Transverse Deflection (in.) } \\
\text { Present Study }\end{array}$ & $\begin{array}{c}\text { Transverse Deflection (in.) } \\
\text { Linear Theory }\end{array}$ \\
\hline 0.0072 & 0.00828 & 0.0083 \\
\hline 0.0145 & 0.01767 & 0.0177 \\
\hline 0.0217 & 0.02651 & 0.0265 \\
\hline 0.0291 & 0.03536 & 0.0353 \\
\hline 0.0363 & 0.04421 & 0.0442 \\
\hline 0.0507 & 0.06188 & 0.0621 \\
\hline
\end{tabular}

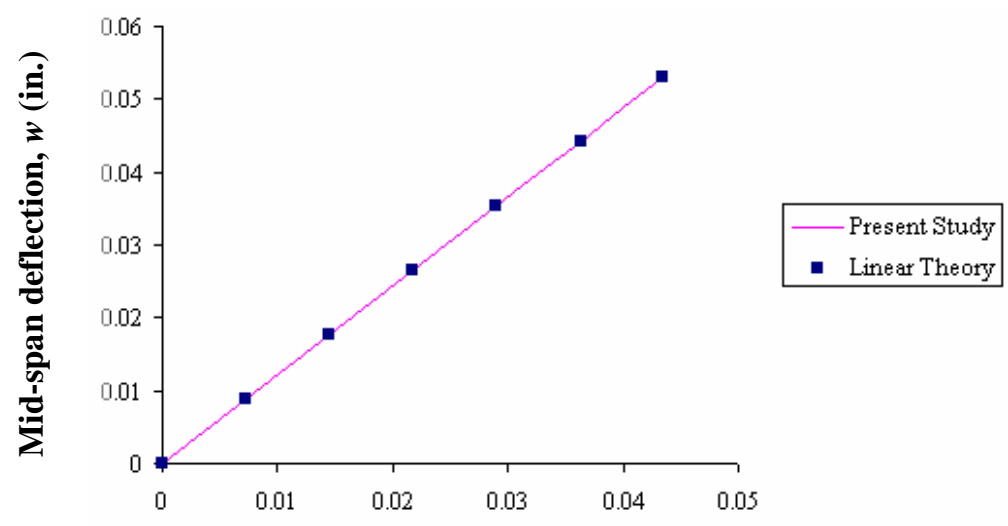

Uniform transverse load (psi)

Figure 4.17 Deflections of clamped-clamped laminate for uniform transverse load in dry condition 


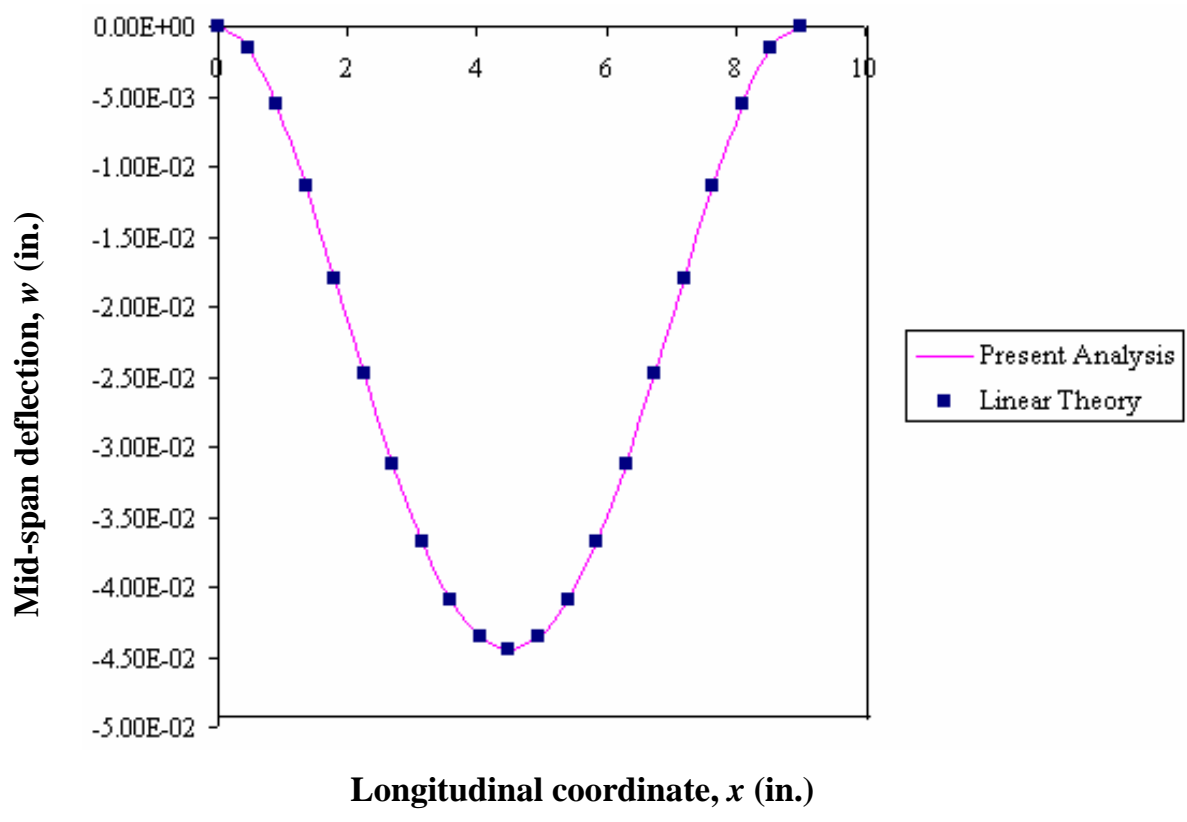

Figure 4.18 Transverse deflection distribution for $0.0363 \mathrm{psi}$

\subsubsection{Transverse Deflections of Pinned-Pinned Laminated Composites Beam under In-Plane Loads}

Tensile normal in-plane loads of varying intensities are applied on outer edges of the laminate. The results are included in Table 4.11 and Figure 4.19, and show good agreement with the ones obtained by linear theory. The deflection along the length of the laminate for the inplane load value of $3.426 \mathrm{lb} / \mathrm{in}$. is shown in Figure 4.20.

Table 4.11 Deflections for pinned-pinned laminate due to in-plane load in dry condition

\begin{tabular}{|c|c|c|}
\hline $\begin{array}{c}\text { In-Plane load } \\
\text { (lb/in.) }\end{array}$ & $\begin{array}{c}\text { Transverse Deflection (in.) } \\
\text { Present study }\end{array}$ & $\begin{array}{c}\text { Transverse Deflection (in.) } \\
\text { Linear Theory }\end{array}$ \\
\hline 0.285 & 0.00145 & 0.00146 \\
\hline 0.571 & 0.00291 & 0.00292 \\
\hline 1.713 & 0.00875 & 0.00875 \\
\hline 3.426 & 0.01752 & 0.01751 \\
\hline 5.139 & 0.02630 & 0.02592 \\
\hline 6.852 & 0.03506 & 0.03456 \\
\hline 8.565 & 0.046 & 0.04601 \\
\hline
\end{tabular}




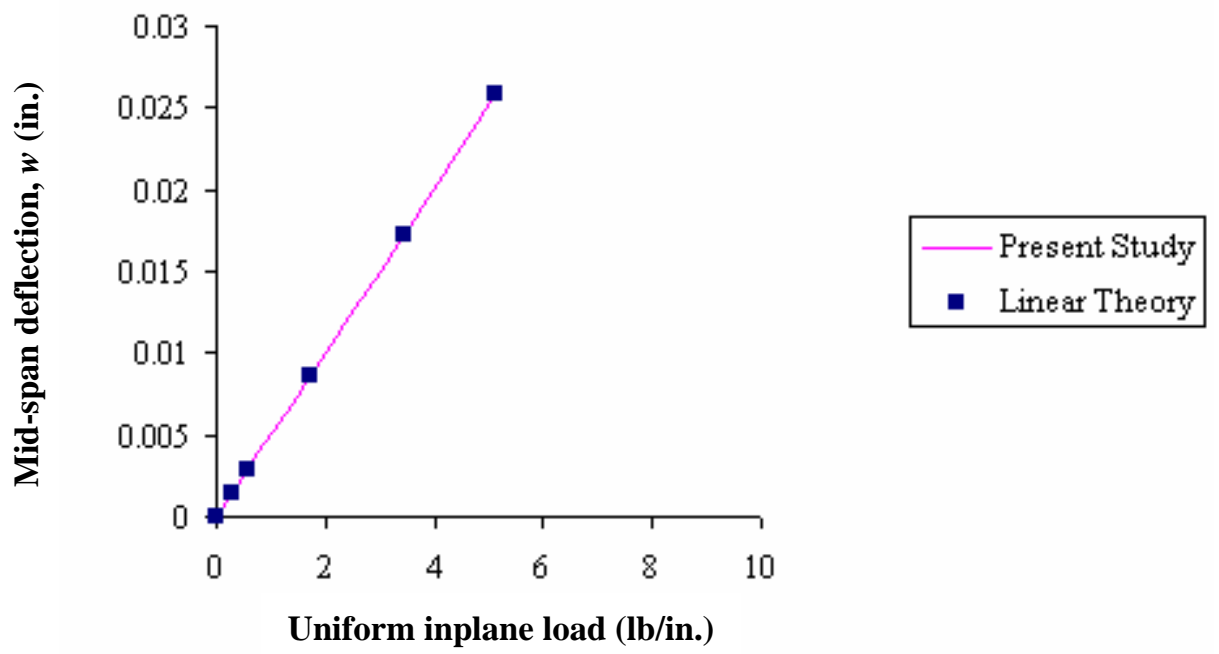

Figure 4.19 Transverse deflection of pinned-pinned laminate under different tensile normal in-plane loads in dry conditions

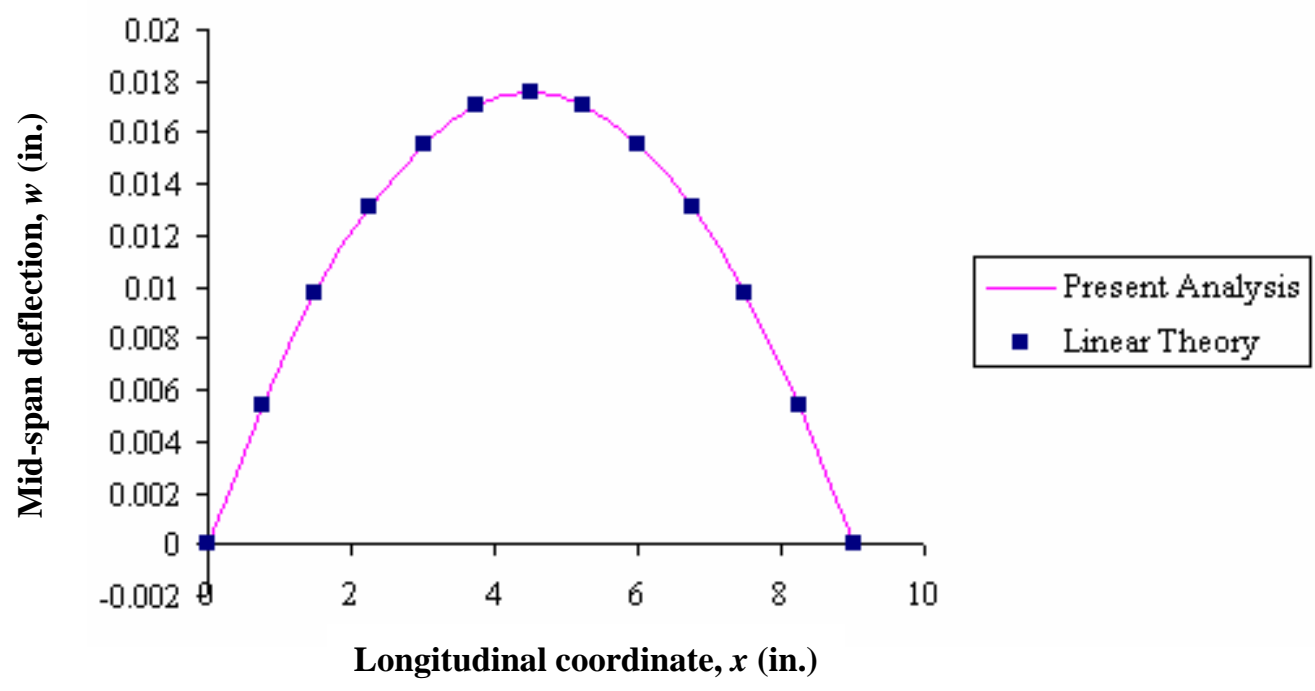

Figure 4.20 Transverse deflection distribution for $3.426 \mathrm{lb} / \mathrm{in}$. 


\subsubsection{Hygrothermal Conditions}

The wet conditions represent a moisture content of $5 \%$ (by weight) and at a temperature of $156.2^{0} \mathrm{~F}$. These values represent the severe atmospheric conditions. The analysis is carried out on pinned and clamped laminates and the maximum centre deflection of the laminates is found. The results are included in Tables 4.12-4.14 and Figures 4.21-4.26 show good agreement with the ones obtained by Upadhyay and Lyons (2000 b).

Table 4.12 Transverse deflections for pinned-pinned laminate due to transverse load for hygrothermal condition

\begin{tabular}{|c|c|c|}
\hline $\begin{array}{c}\text { Transverse Load } \\
\text { (psi) }\end{array}$ & $\begin{array}{c}\text { Transverse Deflection (in.) } \\
\text { Present Study }\end{array}$ & $\begin{array}{c}\text { Transverse Deflection (in.) } \\
\text { Upadhyay and Lyons (2000) }\end{array}$ \\
\hline 0.0058 & 0.0280 & 0.028 \\
\hline 0.0116 & 0.0561 & 0.056 \\
\hline 0.0174 & 0.0842 & 0.084 \\
\hline 0.0232 & 0.1122 & 0.112 \\
\hline 0.0348 & 0.1683 & 0.168 \\
\hline 0.0406 & 0.1964 & 0.196 \\
\hline 0.0581 & 0.2805 & 0.28 \\
\hline 0.1 & 0.4933 & 0.49 \\
\hline
\end{tabular}

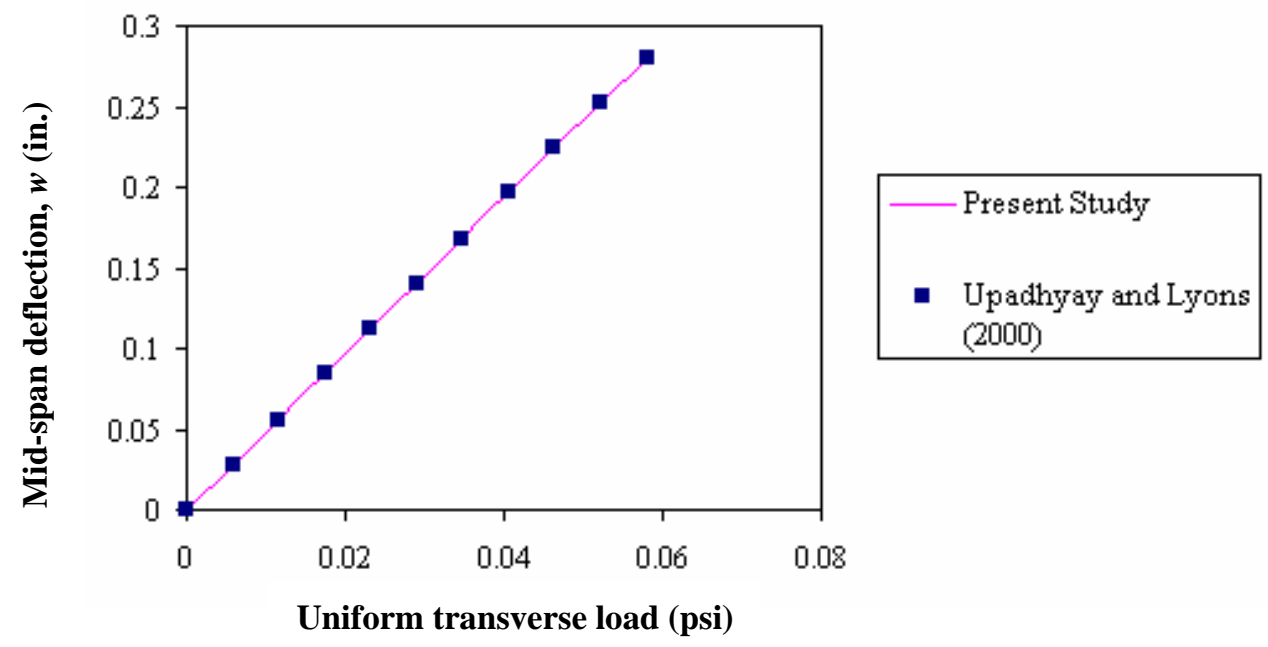

Figure 4.21 Transverse deflections of pinned-pinned laminate for different uniform transverse loads in hygrothermal condition 


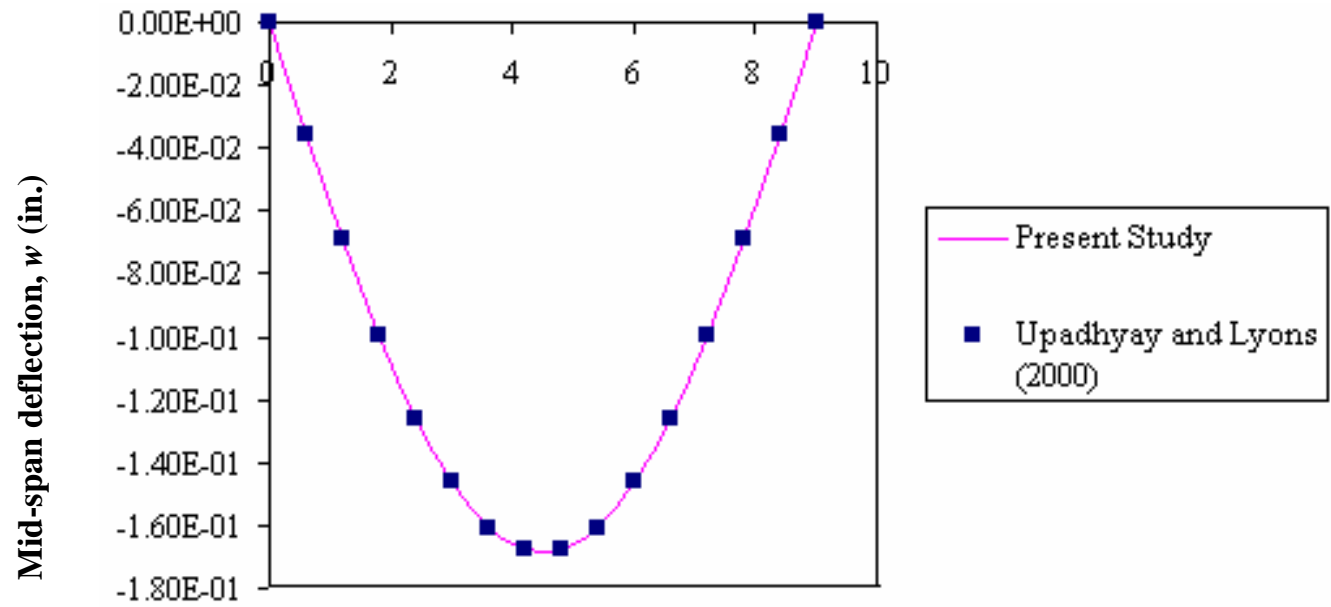

Longitudinal coordinate, $x$ (in.)

Figure 4.22 Transverse deflection distribution for $0.0348 \mathrm{psi}$

Table 4.13 Transverse deflections for clamped-clamped laminate due to transverse load in hygrothermal condition

\begin{tabular}{|c|c|c|}
\hline $\begin{array}{l}\text { Transverse load } \\
\text { (psi) }\end{array}$ & $\begin{array}{l}\text { Transverse deflection (in.) } \\
\text { Present Study }\end{array}$ & $\begin{array}{l}\text { Transverse deflection (in.) } \\
\text { Upadhyay and Lyons (2000) }\end{array}$ \\
\hline 0.0072 & 0.01259 & 0.012 \\
\hline 0.0145 & 0.02608 & 0.026 \\
\hline 0.0217 & 0.03913 & 0.039 \\
\hline 0.0291 & 0.05217 & 0.052 \\
\hline 0.0363 & 0.06523 & 0.065 \\
\hline 0.0435 & 0.07826 & 0.078 \\
\hline 0.0507 & 0.09132 & 0.091 \\
\hline 0.0581 & 0.10431 & 0.104 \\
\hline
\end{tabular}




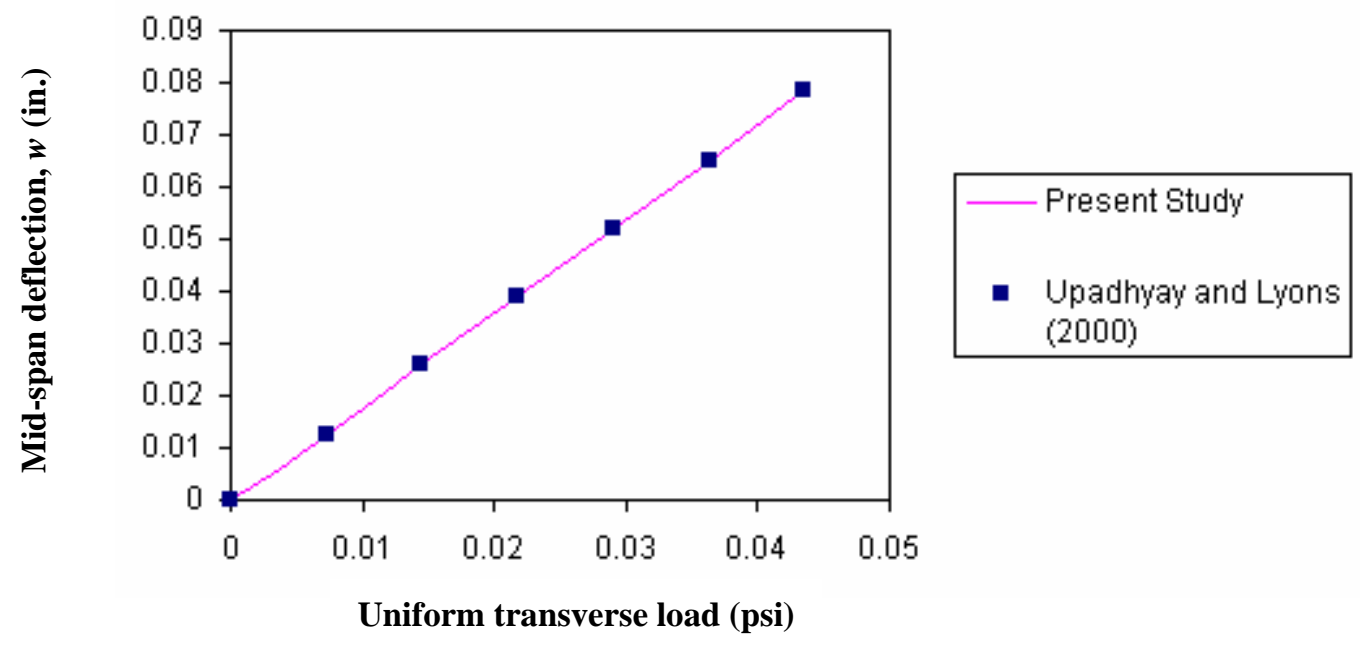

Figure 4.23 Deflections of clamped-clamped laminate due to transverse loads in hygrothermal condition

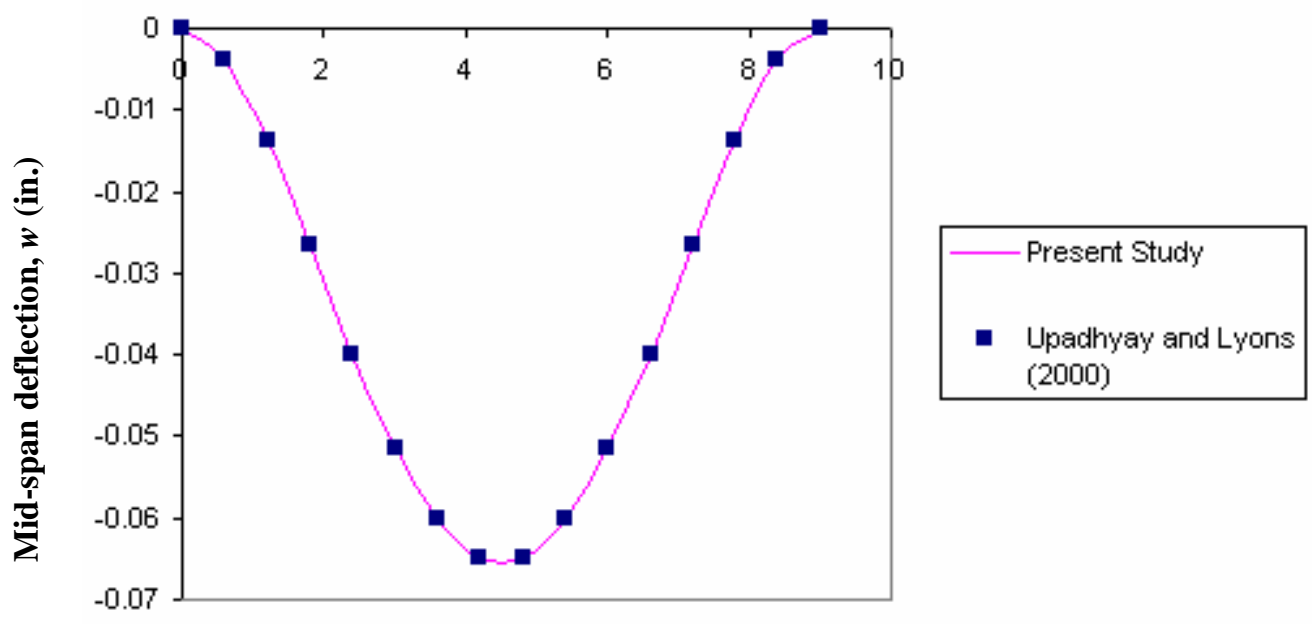

Longitudinal coordinate, $x$ (in.)

Figure 4.24 Transverse deflection distribution for $0.03626 \mathrm{psi}$ 
Table 4.14 Transverse deflections for pinned-pinned laminate due to in-plane loads in hygrothermal condition

\begin{tabular}{|c|c|c|}
\hline $\begin{array}{l}\text { In-plane load } \\
\text { (lb/in.) }\end{array}$ & $\begin{array}{l}\text { Transverse Deflection, (in.) } \\
\text { Present study }\end{array}$ & $\begin{array}{l}\text { Transverse Deflection (in.) } \\
\text { Upadhyay and Lyons (2000) }\end{array}$ \\
\hline 0.2855 & 0.0025 & 0.0026 \\
\hline 0.571 & 0.0051 & 0.0051 \\
\hline 1.713 & 0.0154 & 0.0151 \\
\hline 3.426 & 0.0308 & 0.0311 \\
\hline 5.139 & 0.0463 & 0.0461 \\
\hline 6.852 & 0.0617 & 0.0621 \\
\hline 8.565 & 0.0763 & 0.0762 \\
\hline
\end{tabular}

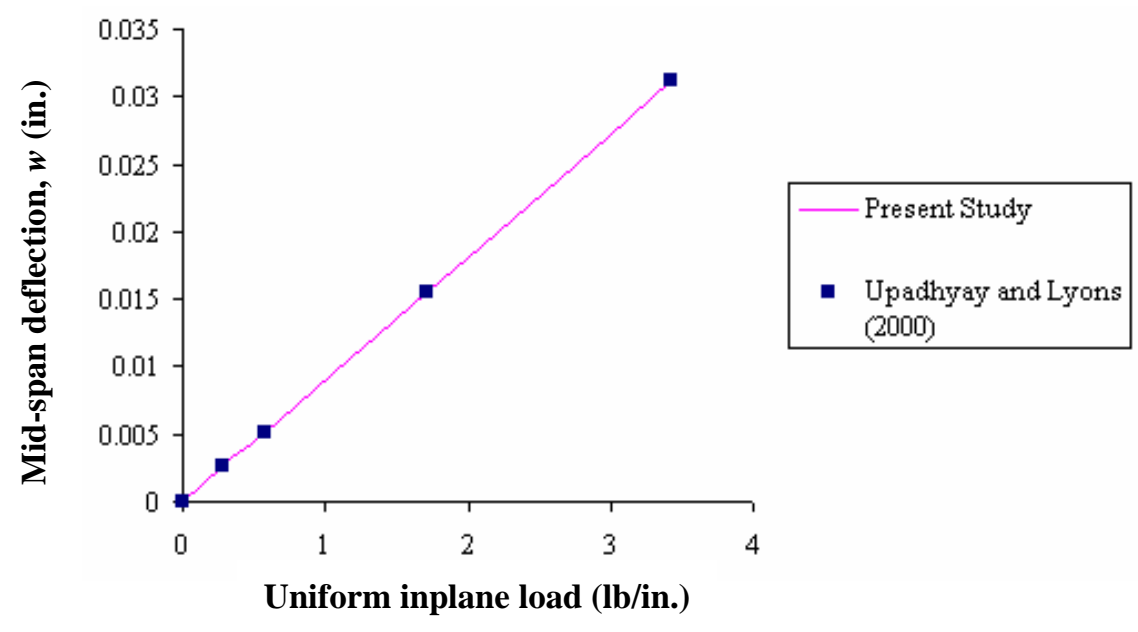

Figure 4.25 Transverse deflections for pinned-pinned laminates for different inplane loads in hygrothermal conditions 


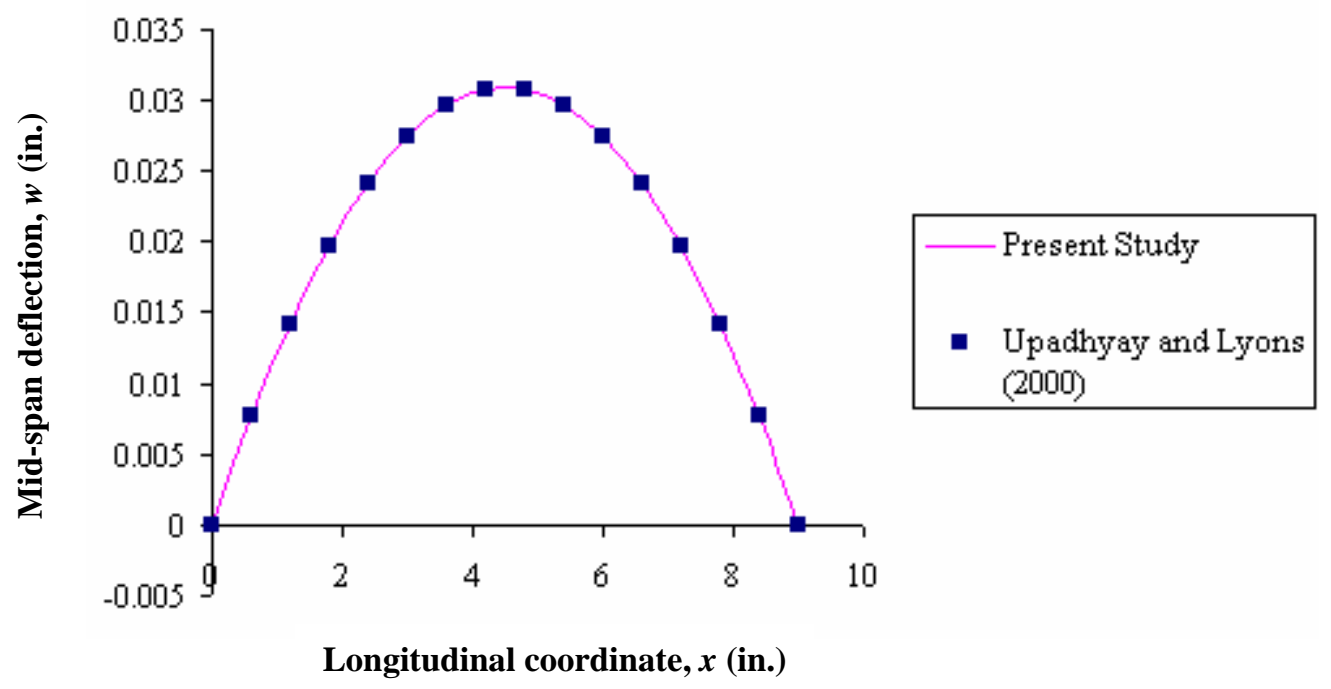

Figure 4.26 Transverse deflection distribution for $3.426 \mathrm{lb} / \mathrm{in}$.

\subsection{Comparison of Hygrothermal Deflections with that of Dry conditions for Laminate under Cylindrical Bending}

In this section, the wet and dry results for the laminate under cylindrical bending are compared. The first set of results (Table 4.15 and Figure 4.27) corresponds to the case of a pinned-pinned laminate subjected to a uniform transverse load. As expected, the dry condition plot of the transverse load versus mid-span deflection is linear whereas its wet counterpart exhibits slightly nonlinear behavior. The effect of the hygrothermal environment is an increase in the mid-span deflection that ranges from $16.58 \%$ to $16.94 \%$.

The corresponding results for the case of clamped-clamped laminate subjected to transverse loads are presented in Table 4.16 and Figure 4.28. The trends are similar to the pinned-pinned case except that the percentage differences are more than twice that of the previous case. 
The comparison for a pinned-pinned laminate subjected to an in-plane load is shown in Table 4.17 and Figure 4.29. The deviation due to hygrothermal conditions is much higher in this case than the previous two cases. The percentage increase in midspan deflection is almost constant for different values of $N_{x}$ at about $76 \%$.

Table 4.15 Dry and wet condition mid-span deflections of pinned laminate under transverse load

\begin{tabular}{|c|c|c|c|}
\hline $\begin{array}{c}\text { Transverse Load } \\
\text { (psi) }\end{array}$ & $\begin{array}{c}\text { Dry Conditions } \\
\text { (in.) }\end{array}$ & $\begin{array}{c}\text { Hygrothermal Conditions } \\
\text { (in.) }\end{array}$ & $\begin{array}{c}\text { Percentage } \\
\text { Difference }\end{array}$ \\
\hline 0.0058 & 0.024 & 0.028 & 16.66 \\
\hline 0.0116 & 0.048 & 0.056 & 16.87 \\
\hline 0.0174 & 0.072 & 0.084 & 16.94 \\
\hline 0.0232 & 0.096 & 0.112 & 16.87 \\
\hline 0.029 & 0.124 & 0.145 & 16.93 \\
\hline 0.0348 & 0.144 & 0.168 & 16.66 \\
\hline 0.0406 & 0.168 & 0.196 & 16.66 \\
\hline 0.0464 & 0.193 & 0.225 & 16.58 \\
\hline 0.0522 & 0.216 & 0.252 & 16.66 \\
\hline
\end{tabular}

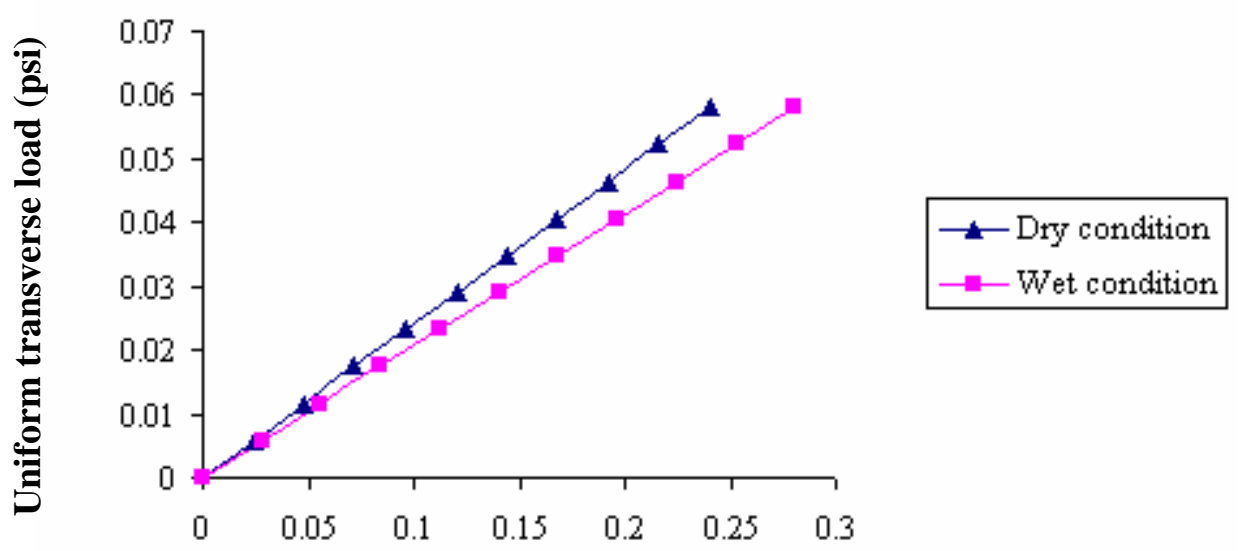

Mid-span deflection, $w$ (in.)

Figure 4.27 Dry and wet condition mid-span deflections of pinned laminate under transverse load 
Table 4.16 Dry and wet condition mid-span deflections of clamped laminate under transverse load

\begin{tabular}{|c|c|c|c|}
\hline $\begin{array}{c}\text { Transverse load } \\
\text { (psi) }\end{array}$ & $\begin{array}{c}\text { Dry conditions } \\
\text { (in.) }\end{array}$ & $\begin{array}{c}\text { Hygrothermal Conditions } \\
\text { (in.) }\end{array}$ & $\begin{array}{c}\text { Percentage } \\
\text { Difference }\end{array}$ \\
\hline 0.0145 & 0.01767 & 0.02608 & 47.59 \\
\hline 0.0217 & 0.02651 & 0.03913 & 47.61 \\
\hline 0.0291 & 0.03536 & 0.05217 & 47.54 \\
\hline 0.0363 & 0.04420 & 0.06523 & 47.57 \\
\hline 0.0435 & 0.05303 & 0.07826 & 47.57 \\
\hline 0.0507 & 0.06188 & 0.09132 & 47.57 \\
\hline 0.0581 & 0.07072 & 0.10431 & 47.49 \\
\hline
\end{tabular}

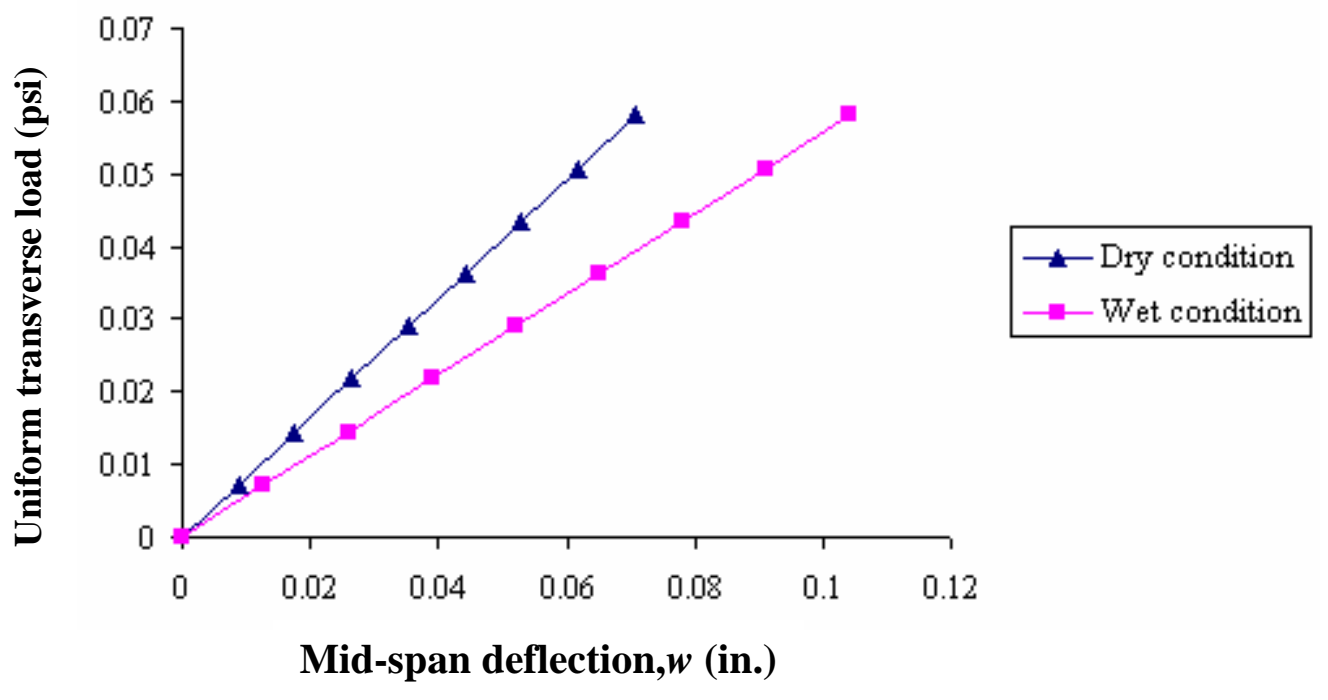

Figure 4.28 Dry and wet condition mid-span deflections of clamped laminate uniform transverse load 
Table 4.17 Dry and wet condition mid-span deflections of pinned laminate under inplane load

\begin{tabular}{|c|c|c|c|}
\hline $\begin{array}{c}\text { In-Plane load } \\
\text { (lb/in.) }\end{array}$ & $\begin{array}{c}\text { Dry conditions } \\
\text { (in.) }\end{array}$ & $\begin{array}{c}\text { Hygrothermal conditions } \\
\text { (in.) }\end{array}$ & Percentage Difference \\
\hline 0.285 & 0.00145 & 0.00257 & 76.33 \\
\hline 0.571 & 0.00291 & 0.00514 & 76.33 \\
\hline 1.713 & 0.00874 & 0.01542 & 76.27 \\
\hline 3.426 & 0.01749 & 0.03085 & 76.21 \\
\hline 5.139 & 0.02624 & 0.04627 & 75.96 \\
\hline 6.852 & 0.03499 & 0.06170 & 75.95 \\
\hline 8.565 & 0.04374 & 0.07713 & 76.33 \\
\hline
\end{tabular}

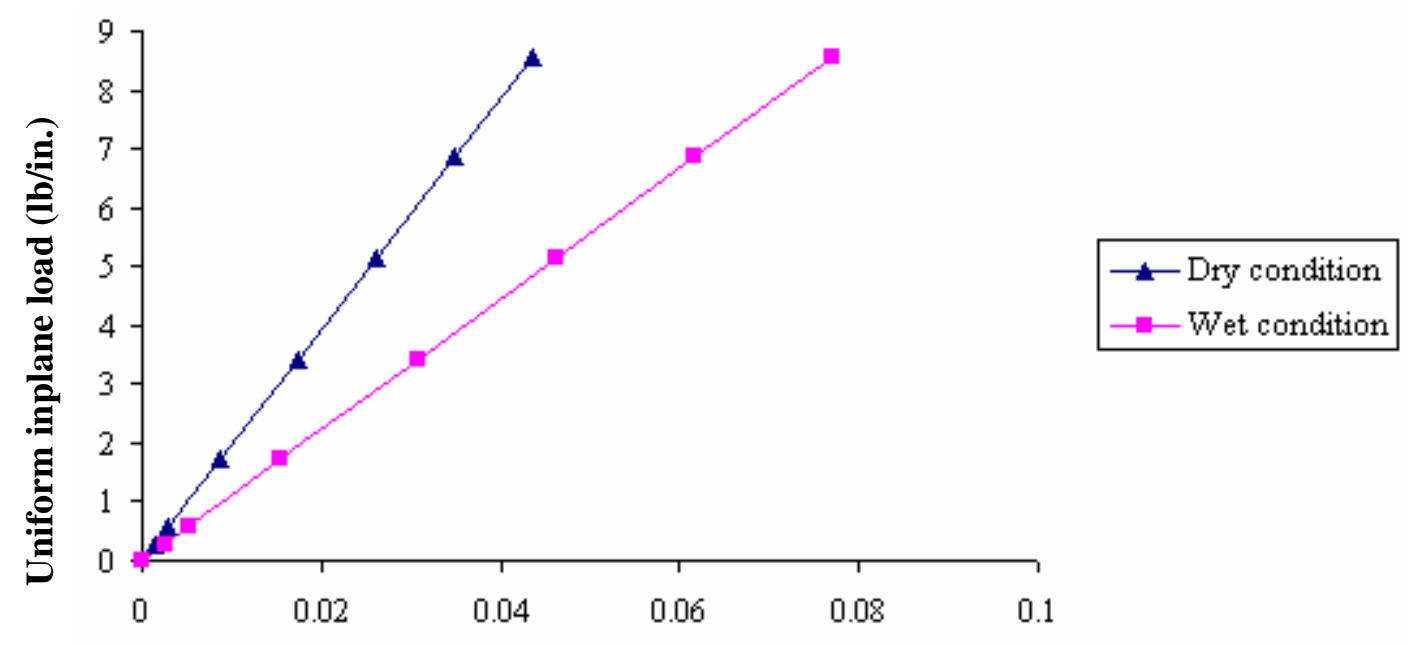

Mid-span deflection, $w$ (in.)

Figure 4.29 Dry and wet condition mid-span deflections of pinned-pinned laminate under uniform in-plane loads

\subsection{Composite Beam subjected to Moving Loads under Hygrothermal Environment}

Having validated the moving load model and the hygrothermal model, the two effects are combined in this phase of the analysis. A simply supported composite laminated beam has a moving load of constant magnitude traveling from the left end to 
the right end with a constant velocity and the beam is subjected to a hygrothermal environment. The dynamic magnification factors of the mid-span deflection are calculated. A parametric study is carried out by varying the fiber volume fraction of the lamina and by considering different laminates. First a static analysis under dry and wet conditions is carried out to get the baseline mid-span deflections.

For wet conditions, the matrix properties are degraded using Eq.(2.1), and then the lamina properties are calculated using the rule of mixtures, Eq.(2.3,2.4, and 2.5).

\subsubsection{STATIC ANALYSIS}

The temperature and moisture content in dry conditions are taken as $72^{0} \mathrm{~F}$ and 0 \% respectively. For hygrothermal conditions, the temperature and moisture content are taken as $154.2^{0} \mathrm{~F}$ and $5 \%$ respectively. The beam geometric properties are as follows:

Length $=4$ in .

Width $=0.25$ in.

Thickness $=0.293$ in .

Tables (4.18, 4.19, and 4.20) provide the material properties for fiber volume fractions of 0.52, 0.6 and 0.7, respectively under dry and hygrothermal conditions.

Table 4.18 Material properties for fiber volume fraction of 0.52

\begin{tabular}{|l|l|l|}
\hline \multicolumn{1}{|c|}{ Property } & Dry Condition & Hygrothermal Condition \\
\hline Longitudinal modulus, $E_{1}$ & $6.82 \times 10^{6} \mathrm{psi}$ & $6.64 \times 10^{6} \mathrm{psi}$ \\
\hline Transverse modulus, $E_{2}$ & $1.23 \times 10^{6} \mathrm{psi}$ & $0.59 \times 10^{6} \mathrm{psi}$ \\
\hline Longitudinal Shear Modulus, $G_{12}$ & $0.46 \times 10^{6} \mathrm{psi}$ & $0.42 \times 10^{6} \mathrm{psi}$ \\
\hline Transverse Shear Modulus, $G_{13}$ & $0.46 \times 10^{6} \mathrm{psi}$ & $0.42 \times 10^{6} \mathrm{psi}$ \\
\hline Inter laminar Shear Modulus, $G_{23}$ & $0.58 \times 10^{6} \mathrm{psi}$ & $0.56 \times 10^{6} \mathrm{psi}$ \\
\hline Major in-plane Poisson's ratio, $v_{12}$ & 0.25 & 0.25 \\
\hline Out of plane Poisson's ratio, $v_{23}$ & 0.25 & 0.25 \\
\hline Out of plane Poisson's ratio, $v_{13}$ & 0.25 & 0.25 \\
\hline
\end{tabular}


Table 4.19 Material properties for fiber volume fraction of $\mathbf{0 . 6}$

\begin{tabular}{|l|l|l|}
\hline \multicolumn{1}{|c|}{ Property } & Dry Condition & Hygrothermal Condition \\
\hline Longitudinal modulus, $E_{1}$ & $7.75 \times 10^{6} \mathrm{psi}$ & $7.62 \times 10^{6}$ \\
\hline Transverse modulus, $E_{2}$ & $1.44 \times 10^{6}$ & $0.70 \times 10^{6}$ \\
\hline Longitudinal Shear Modulus, $G_{12}$ & $0.54 \times 10^{6}$ & $0.32 \times 10^{6}$ \\
\hline Transverse Shear Modulus, $G_{13}$ & $0.54 \times 10^{6}$ & $0.37 \times 10^{6}$ \\
\hline Inter laminar Shear Modulus, $G_{23}$ & $0.70 \times 10^{6}$ & $0.62 \times 10^{6}$ \\
\hline Major in-plane Poisson's ratio, $v_{12}$ & 0.25 & 0.25 \\
\hline Out of plane Poisson's ratio, $v_{23}$ & 0.25 & 0.25 \\
\hline Out of plane Poisson's ratio, $v_{13}$ & 0.25 & 0.25 \\
\hline
\end{tabular}

Table 4.20 Material properties for fiber volume fraction of 0.7

\begin{tabular}{|l|l|l|}
\hline \multicolumn{1}{|c|}{ Property } & Dry Condition & Hygrothermal Condition \\
\hline Longitudinal modulus, $E_{1}$ & $8.94 \times 10^{6} \mathrm{psi}$ & $8.84 \times 10^{6} \mathrm{psi}$ \\
\hline Transverse modulus, $E_{2}$ & $1.85 \times 10^{6} \mathrm{psi}$ & $0.92 \times 10^{6} \mathrm{psi}$ \\
\hline Longitudinal Shear Modulus, $G_{12}$ & $0.69 \times 10^{6} \mathrm{psi}$ & $0.32 \times 10^{6} \mathrm{psi}$ \\
\hline Transverse Shear Modulus, $G_{13}$ & $0.69 \times 10^{6} \mathrm{psi}$ & $0.32 \times 10^{6} \mathrm{psi}$ \\
\hline Inter laminar Shear Modulus, $G_{23}$ & $0.93 \times 10^{6} \mathrm{psi}$ & $0.90 \times 10^{6} \mathrm{psi}$ \\
\hline Major in-plane Poisson's ratio, $v_{12}$ & 0.25 & 0.25 \\
\hline Out of plane Poisson's ratio, $v_{23}$ & 0.25 & 0.25 \\
\hline Out of plane Poisson's ratio, $v_{13}$ & 0.25 & 0.25 \\
\hline
\end{tabular}

The laminate configurations that are taken in this analysis are

1) $0 / 90 /-15 /-15$

2) $0 / 90 /-30 / 30$

3) $0 / 90 /-45 / 45$

The beam is simply supported and a load of $1 \mathrm{lb}$ is applied at the center of the beam.

Table (4.21) gives the mid-span static deflection under dry and hygrothermal conditions, for the three fiber volume fractions and the three laminates considered. 
Table 4.21 Static mid-span deflection of beams made of various laminate configurations

\begin{tabular}{|l|l|c|c|}
\hline Fiber volume fraction, 0.52 & Lay-up & Dry Condition (in.) & $\begin{array}{l}\text { Hygrothermal } \\
\text { Condition (in.) }\end{array}$ \\
\hline \multirow{3}{*}{} & $0 / 90 /-15 / 15$ & $1 \times 10^{-3}$ & $1.22 \times 10^{-3}$ \\
\cline { 2 - 4 } & $0 / 90 /-30 / 30$ & $0.989 \times 10^{-3}$ & $1.15 \times 10^{-3}$ \\
\cline { 2 - 4 } & $0 / 90 /-45 / 45$ & $0.897 \times 10^{-3}$ & $0.986 \times 10^{-3}$ \\
\hline Fiber volume fraction, 0.6 & $0 / 90 /-15 / 15$ & $0.868 \times 10^{-3}$ & $1.06 \times 10^{-3}$ \\
\hline & $0 / 90 /-30 / 30$ & $0.858 \times 10^{-3}$ & $1.03 \times 10^{-3}$ \\
\cline { 2 - 4 } & $0 / 90 /-45 / 45$ & $0.779 \times 10^{-3}$ & $0.901 \times 10^{-3}$ \\
\hline Fiber volume fraction, 0.7 & $0 / 90 /-15 / 15$ & $0.722 \times 10^{-3}$ & $0.912 \times 10^{-3}$ \\
\hline & $0 / 90 /-30 / 30$ & $0.716 \times 10^{-3}$ & $0.888 \times 10^{-3}$ \\
\hline & $0 / 90 /-45 / 45$ & $0.651 \times 10^{-3}$ & $0.803 \times 10^{-3}$ \\
\hline
\end{tabular}

\subsubsection{DYNAMIC ANALYSIS}

Dynamic transient analysis is performed on the above stated laminates. A force of magnitude $1 \mathrm{lb}$ moving with a velocity of $102.33 \mathrm{ft} / \mathrm{s}$ (69.77) is applied on these simply supported beams. The maximum dynamic mid-span deflections in inches are presented in Table (4.22). 
Table 4.22 Dynamic mid-span deflections of beams made of various laminate configurations

\begin{tabular}{|l|l|c|c|}
\hline Fiber volume fraction, 0.52 & Lay-up & Dry Condition (in.) & $\begin{array}{l}\text { Hygrothermal } \\
\text { Condition (in.) }\end{array}$ \\
\hline & $0 / 90 /-15 / 15$ & $1.15 \times 10^{-3}$ & $1.43 \times 10^{-3}$ \\
\cline { 2 - 4 } & $0 / 90 /-30 / 30$ & $1.14 \times 10^{-3}$ & $1.32 \times 10^{-3}$ \\
\cline { 2 - 4 } & $0 / 90 /-45 / 45$ & $0.98 \times 10^{-3}$ & $1.13 \times 10^{-3}$ \\
\hline Fiber volume fraction, 0.6 & $0 / 90 /-15 / 15$ & $0.93 \times 10^{-3}$ & $1.23 \times 10^{-3}$ \\
\hline & $0 / 90 /-30 / 30$ & $0.92 \times 10^{-3}$ & $1.19 \times 10^{-3}$ \\
\cline { 2 - 4 } & $0 / 90 /-45 / 45$ & $0.91 \times 10^{-3}$ & $0.99 \times 10^{-3}$ \\
\hline Fiber volume fraction, 0.7 & $0 / 90 /-15 / 15$ & $0.76 \times 10^{-3}$ & $1.01 \times 10^{-3}$ \\
\hline & $0 / 90 /-30 / 30$ & $0.73 \times 10^{-3}$ & $0.98 \times 10^{-3}$ \\
\hline & $0 / 90 /-45 / 45$ & $0.69 \times 10^{-3}$ & $0.88 \times 10^{-3}$ \\
\hline
\end{tabular}

\subsubsection{Dynamic Magnification Factors (DMF)}

The dynamic magnification factor (DMF) is the ratio of the maximum dynamic mid-span deflection to the static deflection at the mid-span. The magnification factors for the spectrum of the analysis are listed in Table (4.23). The DMF are also plotted in Figures 4.30, 4.31 and 4.32. 
Table 4.23 Dynamic magnification factors for different lay-ups and $V_{\boldsymbol{f}}$

\begin{tabular}{|l|l|c|c|}
\hline Fiber volume fraction, 0.52 & Lay-up & Dry Condition & $\begin{array}{l}\text { Hygrothermal } \\
\text { Condition }\end{array}$ \\
\hline \multirow{3}{*}{} & $0 / 90 /-15 / 15$ & 1.150 & 1.172 \\
\cline { 2 - 4 } & $0 / 90 /-30 / 30$ & 1.152 & 1.145 \\
\cline { 2 - 4 } & $0 / 90 /-45 / 45$ & 1.224 & 1.146 \\
\hline Fiber volume fraction, 0.6 & $0 / 90 /-15 / 15$ & 1.077 & 1.162 \\
\hline & $0 / 90 /-30 / 30$ & 1.069 & 1.156 \\
\cline { 2 - 4 } & $0 / 90 /-45 / 45$ & 1.155 & 1.101 \\
\hline Fiber volume fraction, 0.7 & $0 / 90 /-15 / 15$ & 1.055 & 1.109 \\
\hline & $0 / 90 /-30 / 30$ & 1.025 & 1.111 \\
\hline & $0 / 90 /-45 / 45$ & 1.061 & 1.1 \\
\hline
\end{tabular}

It can be observed that as the fiber volume fraction of the laminate increases, the deflection decreases for the same laminate configuration. This is due to increase in stiffness of the laminate.

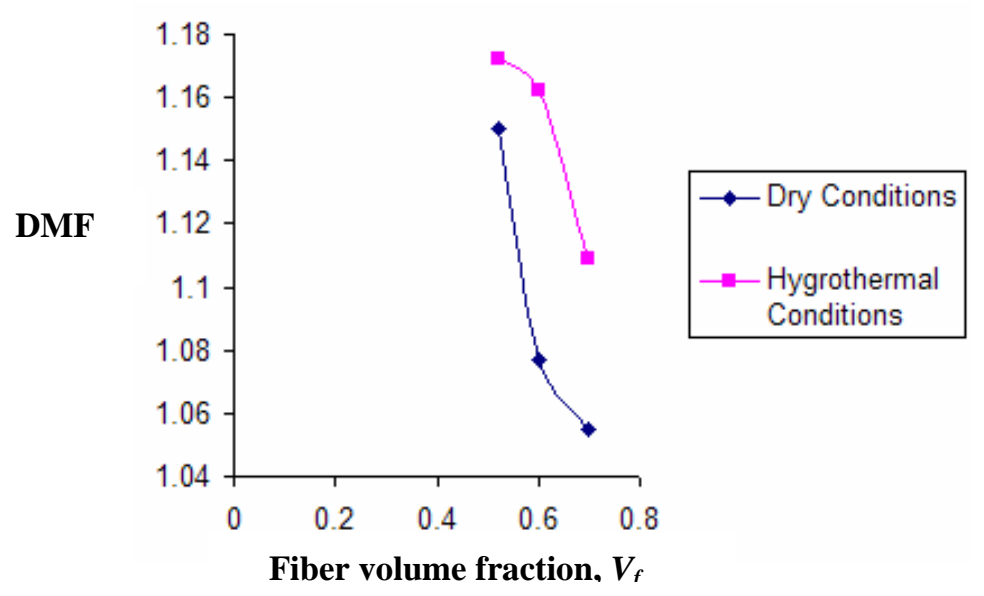

Figure 4.30 Dynamic magnification factor for 0/90/-15/15 laminate 


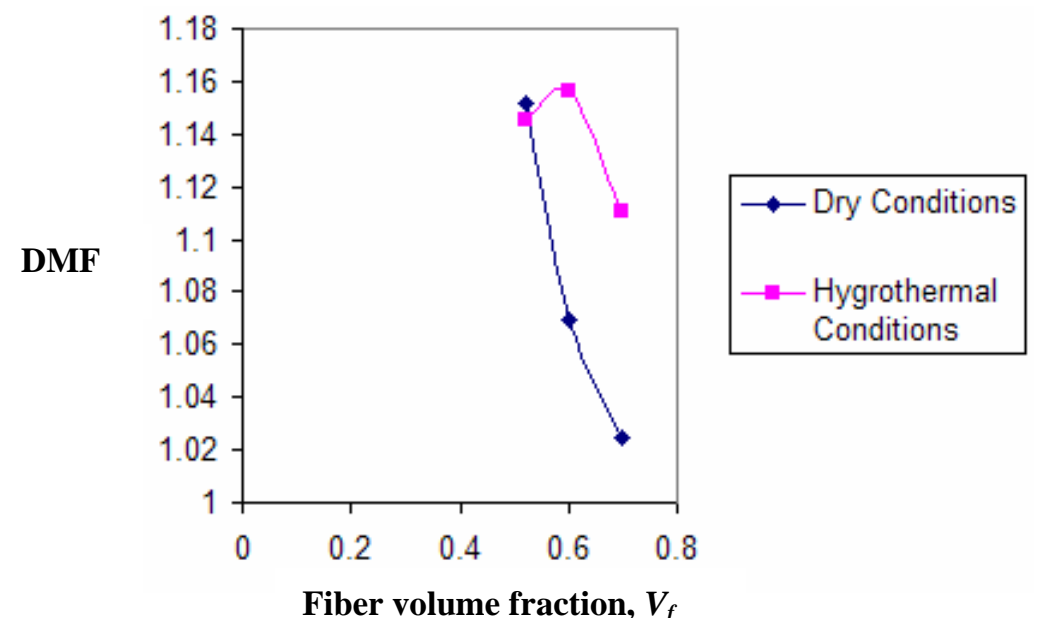

Figure 4.31 Dynamic magnification factor for 0/90/-30/30 laminate

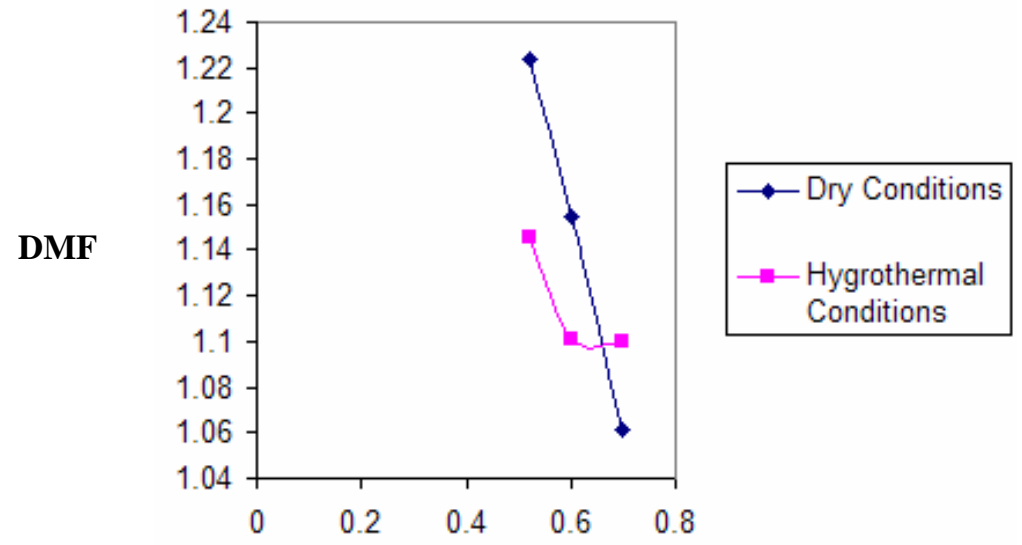

Fiber volume fraction, $V_{f}$

\section{Figure 4.32 Dynamic magnification factor for 0/90/-45/45 laminate}

The ply orientation influences the dynamic behavior of a beam subjected to moving load. The dynamic magnification factors in dry and hygrothermal conditions for the laminates considered generally follow similar pattern. As the fiber volume fraction increases, the dynamic magnification factor generally decreases; the one exception being the 0/90/-30/30 laminate, wherein the dynamic magnification factor slightly increases at the fiber volume fraction of 0.6. In dry conditions, the 0/90/-45/45 laminate has the 
highest DMF when compared to 0/90-15/15 and 0/90/-30/30 laminates. In hygrothermal conditions, 0/90/-15/15 laminate has the highest DMF when compared to 0/90/-30/30 and 0/90/-45/45 laminates. Based on these results a designer can choose the right ply orientations to control the dynamic behavior of laminated beams. 


\section{CONCLUSIONS AND RECOMMENDATIONS}

\subsection{CONTRIBUTIONS}

1. A moving load on a composite laminated beam is modeled using ANSYS.

2. Hygrothermal analysis is carried out on asymmetric composite laminated beams subjected to a moving load.

3. A parametric study of the moving load hygrothermal problem is carried out by varying the fiber volume fraction and ply lay-ups.

\subsection{CONCLUSIONS}

1. Forced vibration analysis of laminated composite beams under the effect of moving loads using finite element method is successfully carried out with the help of a general finite element program like $A N S Y S$.

2. The dynamic magnification factors for isotropic and composite beams are compared. The graph of dynamic magnification factor as a function of moving load velocity for isotropic and composite beams follows the same pattern. The maximum dynamic magnification factor occurs at the velocity ratio of 1.25 , contrary to what one might expect this to occur at a velocity ratio of 1 .

3. In the case of cylindrical bending problems subjected to transverse loads, the effect of the hygrothermal environment is to increase the maximum deflection by $16 \%$ for pinned-pinned case while it is $47 \%$ for the clamped-clamped case.

4. The ply orientation influences the dynamic behavior of a beam subjected to moving load. The dynamic magnification factors in dry and hygrothermal 
conditions for the laminates considered generally follow similar pattern. As the fiber volume fraction increases, the dynamic magnification factor generally decreases; the one exception being the 0/90/-30/30 laminate, wherein the dynamic magnification factor slightly increases at the fiber volume fraction of 0.6.

5. In dry conditions, the 0/90/-45/45 laminate has the highest DMF when compared to $0 / 90-15 / 15$ and $0 / 90 /-30 / 30$ laminates.

6. In hygrothermal conditions, 0/90/-15/15 laminate has the highest DMF when compared to 0/90/-30/30 and 0/90/-45/45 laminates.

7. Based on these results a designer can choose the right ply orientations to control the dynamic behavior of laminated beams.

\subsection{RECOMMENDATIONS}

1. Moving mass analysis may be performed on the beams. The results can be compared with the present study.

2. Multiple moving loads can be considered and the effects may be compared to that of a single moving load.

3. Nonlinear analysis based on large deflection theory may be adopted.

4. The effects of different moisture contents on the dynamic deflections of laminates may also be calculated. 


\section{REFERENCES}

“Ansys 7.0 online documentation,” Ansys Inc.

Gonzalez, A. and O’Brien, E., 2001, “Dynamic Effects of a Five-axle Truck on a Short-span Bridge,” Report submitted to the Civil Engineering Department, University College, Dublin.

Barbero, E.J., 1998, “Introduction to Composite Materials Design,” Taylor and Francis, Philadelphia.

Cairns, D.S. and D.F. Adams, 1984, "Moisture and Thermal Expansion Properties of unidirectional Composite Materials and the Epoxy Matrix," Environmental Effects on Composite Materials, Vol. 2, George S. Springer, Ed. pp.300-316.

Cantieni, R., 1983, “Dynamic Load Tests on Highway Bridges in Switzerland (EMPA Report No. 211), Dubendorf, Switzerland.

Chamis, C.C., 1983, "Simplified Composite Micromechanics Equations for Hygral, Thermal and Mechanical Properties,” NASA Technical Memorandum 83320. Prepared for the Thirty-eighth Annual Conference of the Society of the Plastics Industry, Reinforced Plastics Institute, Houston, TX, pp. 1-10.

Chan, T-H-T and O’Connor, C., 1990, “Vehicle Model for Highway Bridge Impact,” Journal of Structural Engineering, Vol. 116, No.7, pp. 1772-1793.

Chan, T.H.T., Law, S.S., and Yung, T.H., 1998, "Modal Test on an Existing Concrete Bridge: Experience Acquired,” The HKIE Transactions, Vol. 5, No. 3, pp. 8-16.

Chang, D. and Lee, H., 1994, “Impact Factors for Simple-Span Highway Girder Bridges,” Journal of Structural Engineering, Vol. 120, No. 3, pp. 704-715. 
Fafard, M., Laflamme, M., Savard, M., and Bennur, M., 1998, “Dynamic Analysis of Existing Continuous Bridge,” Journal of Bridge Engineering, Vol. 3, No. 1, pp. 28-37.

Kadivar, M.H. and Mohebpour, S.R., 1997, “Forced Vibration of Unsymmetric Laminated Composite Beams under the Action of Moving Loads,” Journal of composites Science and Technology, Vol. 58, No. 10, pp. 1675-1684.

Martin, T.M., Barton, F.W., and Mckeel, W.T., 2000, "Effect of design parameters on the dynamic response of bridges," Report submitted to Virginia Transportation Research Council.

O'Connor C., and Chan, T.H.T., 1988, "Dynamic Wheel Loads from Bridge Strains,” Journal of Structural Engineering, Vol. 114, pp.1703-1723.

Pesterev, A. V., Yang, B., Bergman, L. A., and Tan, C. A., 2003 "Revisiting the moving force problem,” Journal of Sound and Vibration, Vol. 261, No. 1, pp. 75-91.

Pipes, R. B., Vinson, J. R., and Chou, T. W., 1976 "On the Hygrothermal Response of Laminated Composite Systems,” Journal of Composite Materials, Vol. 10, pp. 129-148.

Reddy, J.N., 1997, “Mechanics of Laminated Composite Plates: Theory and Analysis,” CRC Press, Boca Raton, Fla.

Saadeghvaziri, M.A., 1993, “Finite element analysis of highway bridges subjected to moving loads,” Journal of computers and structures, Vol. 49, No. 5, pp. 837-842.

Shen, C. H., and Springer, G. S., 1976, "Moisture Absorption and Desorption of Composite Materials,” Journal of Composite Materials, Vol. 10, pp. 2-20. 
Shen, C.H., and Springer, G.S., 1977, "Effects of Moisture and Temperature on the Tensile Strength of Composite Materials,” Journal of Composite Materials, Vol.11, pp.2-10.

Taheri, M.R., 1987, “Dynamic response of plates to moving loads: structural impedance and finite element methods,” PhD dissertation, Purdue University, IN.

Tita V., Carvalho J. de., Lirani J., 2003, “Theoretical and experimental dynamic analysis of fiber reinforced composite beams," Journal of the Brazilian Society of Mechanical Sciences and Engineering, Vol. 25, pp. 306-310.

Upadhyay, P.C. and Lyons, J.S., 2000a, “Effect of Hygrothermal Environment on the Bending of PMC Laminates under Large Deflection,” Journal of Reinforced Plastics and Composites, Vol.19, No.6, pp. 465-491.

Upadhyay, P.C. and Lyons, J.S., 2000b, "Hygrothermal Effect on the Large Deflection Bending of Asymmetric PMC Laminates,” Journal of Reinforced Plastics and Composites, Vol.19, No. 14, pp. 1094-1111. 